\title{
Reactive trityl derivatives: stabilised carbocation mass-tags for life sciences applications $\dagger$
}

\author{
Alexey V. Ustinov, ${ }^{a}$ Vadim V. Shmanai, ${ }^{b}$ Kaajal Patel, ${ }^{c}$ Irina A. Stepanova, ${ }^{a}$ Igor A. Prokhorenko, ${ }^{a}$ \\ Irina V. Astakhova, ${ }^{a}$ Andrei D. Malakhov,,${ }_{\uparrow}^{a}$ Mikhail V. Skorobogatyi, ${ }^{a}$ Pablo L. Bernad Jr, ${ }^{c}$ Safraz Khan, ${ }^{c}$ \\ Mona Shahgholi, ${ }^{d}$ Edwin M. Southern, ${ }^{e}$ Vladimir A. Korshun*a and Mikhail S. Shchepinov*c
}

\author{
Received 23rd June 2008, Accepted 1st October 2008 \\ First published as an Advance Article on the web 10th November 2008 \\ DOI: 10.1039/b810600b
}

The rational design of novel triarylmethyl (trityl)-based mass tags (MT) for mass-spectrometric (MS) applications is described. We propose a " $\mathrm{pK}_{\mathrm{R}+}$ rule" to correlate the stability of trityl carbocations with their MS performance: trityls with higher $\mathrm{pK}_{\mathrm{R}+}$ values ionise and desorb better. Trityl blocks were synthesised that have high $\mathrm{pK}_{\mathrm{R}+}$ values and are stable in conditions of MS analysis; these MTs can be ionised by matrix as well as irradiation with a $337 \mathrm{~nm}$ nitrogen laser. ${ }^{13} \mathrm{C}$-Labelled tags were prepared for MS quantitation applications. Moreover, the tags were equipped with a variety of functional groups allowing conjugation with different functionalities within (bio)molecules to enhance the MS characteristics of the latter. The MS behaviour of model polycationic trityl compounds with and without the matrix was studied to reveal that poly-trityl clusters are always singly charged under the (MA)LDI-TOF conditions. Several peptide-trityl conjugates were prepared and comparisons revealed a beneficial effect of trityl tags on the conjugate detection in MS. Trityl compounds containing para-methoxy- and dimethylamine groups, as well as a xanthene fragment, showed considerable enhancement in MS detection of model peptides; thus they are promising tools for proteomic applications. Dimethoxytrityl derivatives allow one to distinguish between Arg- and Lys-containing peptides. Maleimido trityl derivatives are suitable for the efficient derivatisation of thiol-containing peptides in pyridine.

\section{Introduction}

The life sciences are increasingly reliant on MS as a universal tool of unmatched versatility. ${ }^{1}$ MS techniques are employed in the "omics" sciences - genomics, ${ }^{2}$ glycomics, ${ }^{3}$ metabolomics ${ }^{4}$ and other areas, and are particularly successful in top-down and bottom-up proteomics approaches, which study complex mixtures of proteins and peptides. ${ }^{1 \mathrm{c}-\mathrm{e}, 5}$ Despite the progress, many issues remain to be improved, such as sample separation, sensitivity, dynamic range, quantitation etc. Ultimately, enhancing the MS ionisation and desorption ability of peptides would still be a highly desired development.

${ }^{a}$ Shemyakin-Ovchinnikov Institute of Bioorganic Chemistry, MiklukhoMaklaya 16/10, Moscow, 117997, Russia.E-mail: korshun@mail.ibch.ru; Fax: +7 495 3306738; Tel: +7 4953306738

${ }^{b}$ Institute of Physical Organic Chemistry, Surganova 13, Minsk, 220072, Belarus

'Tridend Technologies ( a Division of OGT), Sandy Lane, Yarnton, Oxford, OX51PF, UK. E-mail: misha@tridend.com; Fax: +44 1865 842116; Tel: +447766058079

${ }^{d}$ Department of Chemistry, Caltech, Pasadena, CA, 91125, USA

${ }^{\circ}$ OGT IP, Ltd, Begbroke Business \& Science Park, Sandy Lane, Yarnton, Oxford, OX5 $1 P F, U K$

$\dagger$ Electronic supplementary information (ESI) available: Synthetic procedures for compounds $4 \mathbf{a}-\mathbf{f}, \mathbf{5 a}-\mathbf{k}, 7 \mathbf{a}-\mathbf{j}, \mathbf{8}, 10 \mathbf{f}, \mathbf{g}, \mathbf{h}, 11 \mathbf{a}, \mathbf{b}, \mathbf{1 2 a}-\mathbf{h}, 13 \mathbf{a}, \mathbf{c}$, 15a,c-h, 16a,b, 17c,d, 18, 19, 20, 21, 22b,c, 23b,d, 24d, 27b, 28d-h, 29, 31, 34, 35, 36, 37, 38, 39, 42, 43, 44, 45, 54, 55 and 56. See DOI: $10.1039 / \mathrm{b} 810600 \mathrm{~b}$ $\$$ Present address: Department of Chemistry, Texas A \& M University, College Station, TX 77842, USA.
Trityl (triarylmethyl) derivatives easily ionise, desorb, and can be efficiently detected by MS techniques due to stability of corresponding carbocations. ${ }^{6}$ Importantly, ionisation is a result of a laser irradiation and does not require the assistance of a matrix. This has been put to a practical use by employing trityl mass-tags (MT) in combinatorial chemistry ${ }^{6}$ and life sciences areas such as genomics $^{7}$ and proteomics ${ }^{8}$ in combination with (MA)LDI-TOF detection.

Other MT strategies, most notably quaternary amine- ${ }^{9}$ and triphenylphosphonium-based derivatives, ${ }^{9 b, 10}$ have been developed and compared. ${ }^{11}$ The charge on these moieties is permanent (in contrast with trityl derivatives, which acquire the charge upon acidic treatment or irradiation with light). This substantially limits the applications, since it is easier to control the non-quaternary charge on a trityl through substituents on aromatic rings and steric factors than to control/regulate the quaternary charge on nitrogen or phosphorus atoms. In addition, the cleavable bond between the heteroatom and the $\alpha$-carbon (Scheme 1), prior to generation of the cation is a useful tool, which is unavailable with quaternary MTs.

Existing applications can be improved, and new applications for life sciences area and beyond could emerge, provided the trityl core structure is further optimised and equipped with suitable functionalities. Mass spectra of a number of trityls detectable with similar efficiency can be used for precise calibration of mass spectrometers. Furthermore, combinations of trityls with different masses yield spectra resembling bar-coding patterns. This, and the 

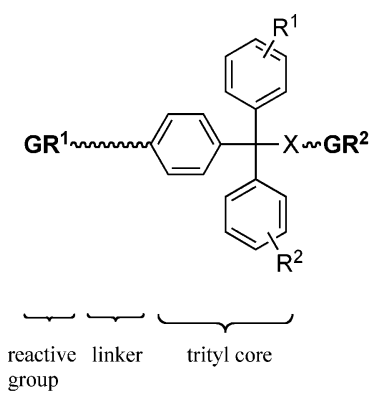

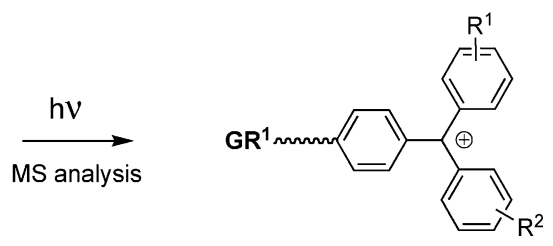

$\mathrm{X}=$ heteroatom $(\mathrm{O}, \mathrm{S}, \mathrm{NH})$

$\mathrm{R}^{1}, \mathrm{R}^{2}$ - trityl cation stabilising groups

a) $\mathbf{G R}^{\mathbf{1}}=$ mass-modifying group, $\mathbf{G R}^{\mathbf{2}}=$ biomolecule

b) $\mathbf{G R}^{1}=$ biomolecule, $\mathbf{G R}^{2}=$ hydroxyl, solid phase, solubility function, etc

Scheme 1 Design of mass-tagging reagents: a) cleavable mass tag, b) covalently attached mass tag.

fact the trityls can be detected at very low concentrations, indicates a potential use of these compounds as security and anti-counterfeit labels. Yet more applications are possible if similarly ionisable trityls with different masses are temporarily attached to some target (bio)molecules or a solid phase through a central atom. One trityl block can be converted into an equally efficiently detectable set of compounds with different masses by taking advantage of, for example, commercially available amines, ${ }^{6}$ and activated ester coupling chemistry ${ }^{7 b, 8 b}$ (variations in $\mathrm{GR}^{1}$, case (a) on Scheme 1).

A mass-tagging tool should contain a reactive group (GR) for attachment to a substrate such as a (bio)molecule; a linker connecting this group to a trityl (with both the linker and the position of attachment being important in the MT performance); and a trityl, capable of producing a stable carbocation prior or during the MS analysis. In this paper, we describe in detail the rational design of trityl compounds and functional moieties permanently attached to aryl groups (case (b) on Scheme 1). The structure of the part attached through an $\mathrm{X}$ heteroatom and bearing $\mathrm{GR}^{2}$, which is disconnected from the MT when the cation is generated, has been reported elsewhere. ${ }^{7 b, 8 b, c}$

The aim of our research was to elucidate the scope and limitations of the use of easily cationised triarylmethyl derivatives as covalently attached tags/enhancers for mass spectrometry of biomolecules, by optimising different parts of a mass-tag structure and investigating the properties of corresponding conjugates. In our quest for more efficient mass-tags we tested a variety of different structures as summarised below.

\section{Results and discussion}

\section{$\mathrm{pK}_{\mathrm{R}+}$ as a measure of trityl stability}

Since the trityl part of the tag is vital for the MS analysis, we will first define the physico-chemical parameter that correlates the structural features of the triarylmethyl group with its MS performance. We found that there is a correlation between the stability of triphenylmethyl carbocations and their propensity for efficient ionisation and desorbtion; trityls which generate more stable cations can be detected at lower concentrations. $\mathrm{pK}_{\mathrm{R}+}$ is used to express the stability of (trityl) cations and to quantify the required acidic conditions to generate those cations. ${ }^{12}$ The single most important factor influencing the stability of triarylmethyl carbocations is the number and position of electron donating and/or cation-stabilising groups. For instance, additional methoxy groups in the ortho or para position of the trityl's phenyl rings stabilise the corresponding cation more, and consequently it is possible to prepare trityl cations stable even under neutral conditions (with $\mathrm{pK}_{\mathrm{R}+}$ in excess of 7.5). ${ }^{13}$

The stability of trityl cations has a direct impact on the MS analysis of these systems. This is well illustrated on Fig. 1, which shows the LDI-TOF MS spectrum of an equimolar mixture of 5 different trityl alcohols. Despite the fact that the analysed sample contained the same number of molecules of each compound, there is an evident correlation between the stability of the cations and the sensitivity of the analysis; the more stable the trityl cation is, the better its detection in MS.

Trityls with high $\mathrm{pK}_{\mathrm{R}+}$ preferably stay in the ionic form (as salts). As we wanted to retain the bond between an $\alpha$-carbon and $\mathrm{X}$ (Fig. 1) for some applications, we set out to design and test trityl blocks with $\mathrm{pK}_{\mathrm{R}+}$ values not exceeding 6 .

\section{Synthesis of trityl blocks}

We used several approaches ${ }^{14}$ to build up a large number of functionalised trityl blocks. Scheme 2 illustrates the approach where the first step is the attachment of the linker to a benzophenone. 4-Hydroxybenzophenones 1-3 were alkylated with two tert-butyl $\omega$-halogenalkanoates, $\mathrm{Cl}\left(\mathrm{CH}_{2}\right)_{3} \mathrm{CO}_{2} \mathrm{Bu}^{t}$ and $\mathrm{Br}\left(\mathrm{CH}_{2}\right)_{5} \mathrm{CO}_{2} \mathrm{Bu}^{t}$, to give ketones 4. tert-Butyl esters are stable enough to allow the reaction of benzophenones $\mathbf{4}$ with arylmagnesiumhalogenides to yield tritanols $\mathbf{5}$. The tert-butyl protecting group in compounds $\mathbf{5}$ was removed using treatment with $\mathrm{CF}_{3} \mathrm{CO}_{2} \mathrm{H}$. The obtained acids 6 can be converted into three activated derivatives - oxysuccinimide esters 7, oxysulfosuccinimide esters $\mathbf{8}$, and pentafluorophenyl esters 9. All these esters can react with amines to yield amides 10.

An alternative approach is shown in Scheme 3. In this case the trityl assembly starts with the lithiation of bromo derivatives $\mathbf{1 1}$ carrying an orthoester-protected carboxy function, followed by reaction with various diarylketones. The orthoester protection of carboxyl is compatible with organolithium reagents, in contrast to $\mathrm{Bu}^{t}$ esters. Tritanols $\mathbf{1 2}$ can be easily purified by column chromatography. Mild acid hydrolysis of the orthoester function gives diol esters 13, and further alkaline hydrolysis leads to acids 


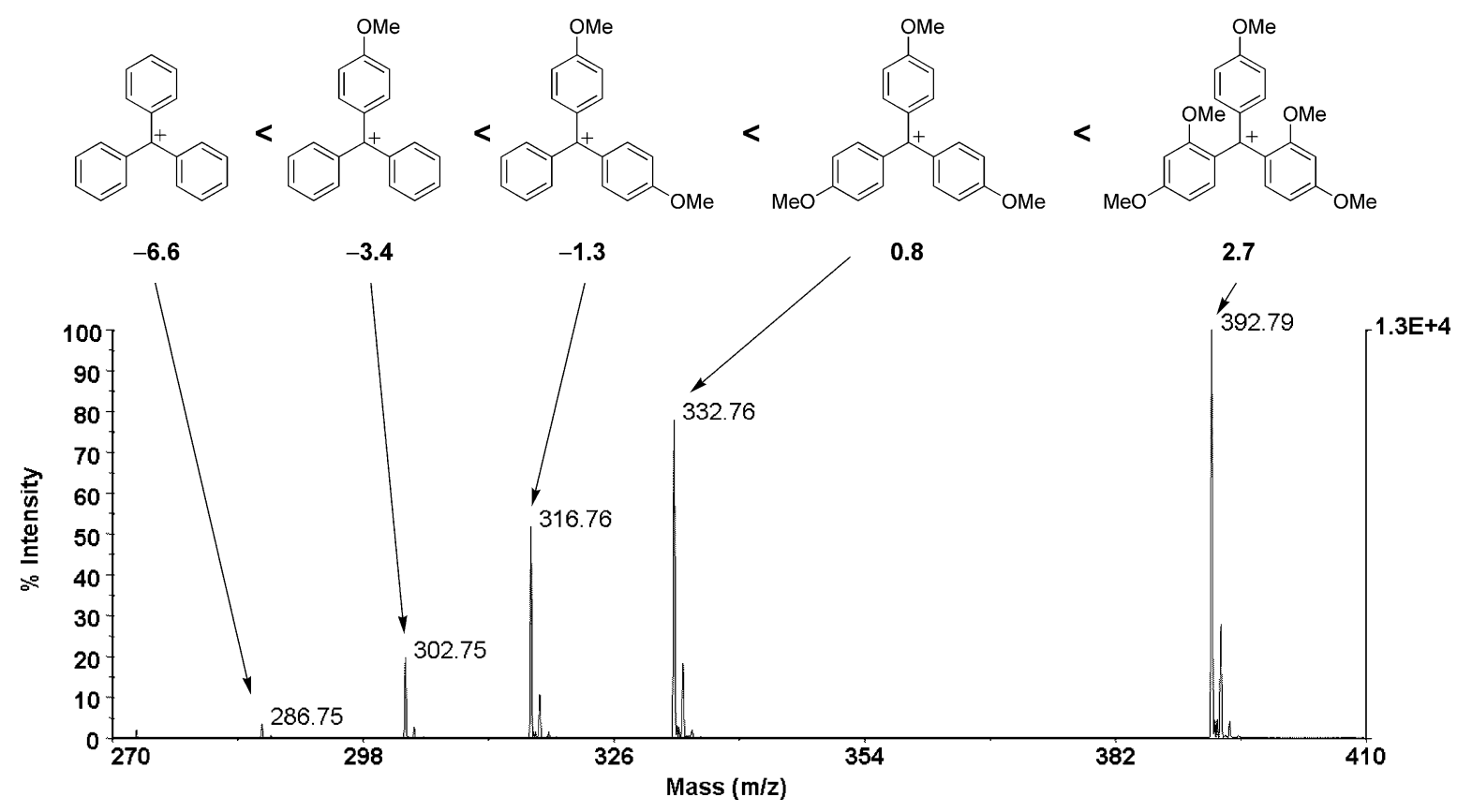

Fig. 1 LDI mass-spectrum of equimolar mixture of $\mathrm{Ph}_{3} \mathrm{COH}$, 4- $\mathrm{MeOC}_{6} \mathrm{H}_{4} \mathrm{CPh}_{2} \mathrm{OH}, \quad\left(4-\mathrm{MeOC}_{6} \mathrm{H}_{4}\right)_{2} \mathrm{CPhOH}, \quad\left(4-\mathrm{MeOC}_{6} \mathrm{H}_{4}\right)_{3} \mathrm{COH}$, and $\left(2,4-(\mathrm{MeO})_{2} \mathrm{C}_{6} \mathrm{H}_{3}\right)_{2} \mathrm{C}\left(4-\mathrm{MeOC}_{6} \mathrm{H}_{4}\right) \mathrm{OH}$; no matrix.

14. The latter were converted to NSu esters $\mathbf{1 5}$ or water-soluble sulfoNSu esters 16. The reaction of activated esters $\mathbf{1 5}$ and $\mathbf{1 6}$ with amines gives amides $\mathbf{1 7}$.

We tested several linker systems (see Scheme 1), aiming at developing an appendage that would give high coupling yields in conjugation reactions, would be stable in MS and would not decrease the $\mathrm{pK}_{\mathrm{R}+}$ of the trityl core. Direct attachment of an activated carboxyl group to one of the phenyls of a trityl, ${ }^{6,15}$ either in the para- or the meta-position, led to a decrease in $\mathrm{pK}_{\mathrm{R}+}$ of a corresponding MT, which had a detrimental effect on the MS detection efficiency. We therefore attached a butyric linking moiety through an oxygen atom, thus retaining the number of alkoxyl groups on the system. Several different compounds were prepared as shown above (7a-c,h, 8 , Scheme $2 ; \mathbf{1 5 g}-\mathbf{h}$, Scheme 3$)$. For applications where cross-linking using the trityl reagent would be required, or for expanding the range of trityl MTs with different masses generated from amine libraries, ${ }^{6,7 a}$ we have also designed trityl blocks bearing two carboxy functions. These were also based on butyric linkers (7e-f, 9, Scheme 2).

This linker was found to be unstable in conditions of (MA)LDITOF MS use, with carbon-oxygen bond fragmenting with release of a quinoidal trityl cation, presumably due to a favourable formation of a 5-membered ring $^{8 b}$ (MS data not shown). To avoid this, we extended the length of the linker by 2 carbons, employing the hexanoic acid based synthon (7d,i, Scheme 2). This linker turned out to be more stable in MS analysis, but still some of the quinoidal cleavage product was detected (MS data not shown), suggesting that a carbon-carbon bond based linker attachment would be a better choice.

This was achieved by a different strategy $(\mathrm{n}=0$; Scheme 3$)$ whereby a synthon 11b was reacted with a variety of ketones, generating trityl blocks with a very MS-stable two-carbon linker.
Xanthone and thioxanthone groups render trityl cations higher stability compared to non-bridged systems, so we prepared several trityl blocks incorporating these moieties. Stability of trityl cations (and trityl ethers) based on a thioxanthone moiety can be manipulated by converting a bridged sulfur atom into a corresponding sulfoxide, which can then be reduced back to sulfide. ${ }^{16}$

To get access to trityl blocks with three para-methoxy groups, we had to attach a linker through a meta-position and introduce a linker into a ketone. Scheme 4 shows the introduction of alkyl linker into dimethoxybenzophenone and the synthesis of several trialkoxytrityls, including one ${ }^{13} \mathrm{C}$-labelled compound. 3Iodo-4,4'-dimethoxybenzophenone (18) was obtained from 3iodo-4-methoxybenzoic acid or, more conveniently, by direct iodination of 4,4'-dimethoxybenzophenone. Compound 18 can be easily demethylated using $\mathrm{BBr}_{3}$ in $\mathrm{DCM}$ to give 3-iodo-4,4'dihydroxybenzophenone 19. The latter was alkylated to yield diethyl ether $\mathbf{2 0}$ and dibenzyl ether 21. Iodo derivatives 18, 20, and 21 underwent a Sonagashira-type coupling reaction with tert-butyl 5-hexynoate. The obtained alkynes $\mathbf{2 2}$ were hydrogenated over $10 \%$ $\mathrm{Pd} / \mathrm{C}$ to give alkyl derivatives 23 . In the course of hydrogenolysis of compounds 22, the alkoxy groups are cleaved and the product is the dihydroxyketone 23c. This was alkylated with $\left[{ }^{13} \mathrm{C}\right]$ ethanol using Mitsunobu conditions to afford 23d. Ketones 22a, 23a,b,d were reacted with $\mathrm{ArMgBr}$ to yield corresponding tritanol derivatives 29 and 24. These were hydrolysed to acids 30 and 25 and further converted into activated oxysuccinimide (31 and 26) or sulfooxysuccinimide (27) esters.

Isotopic labelling is widely used in MS proteomics analysis to distinguish between species with identical masses, for instance for quantitative comparison between peaks corresponding to the same peptide obtained from two different sources. Two 


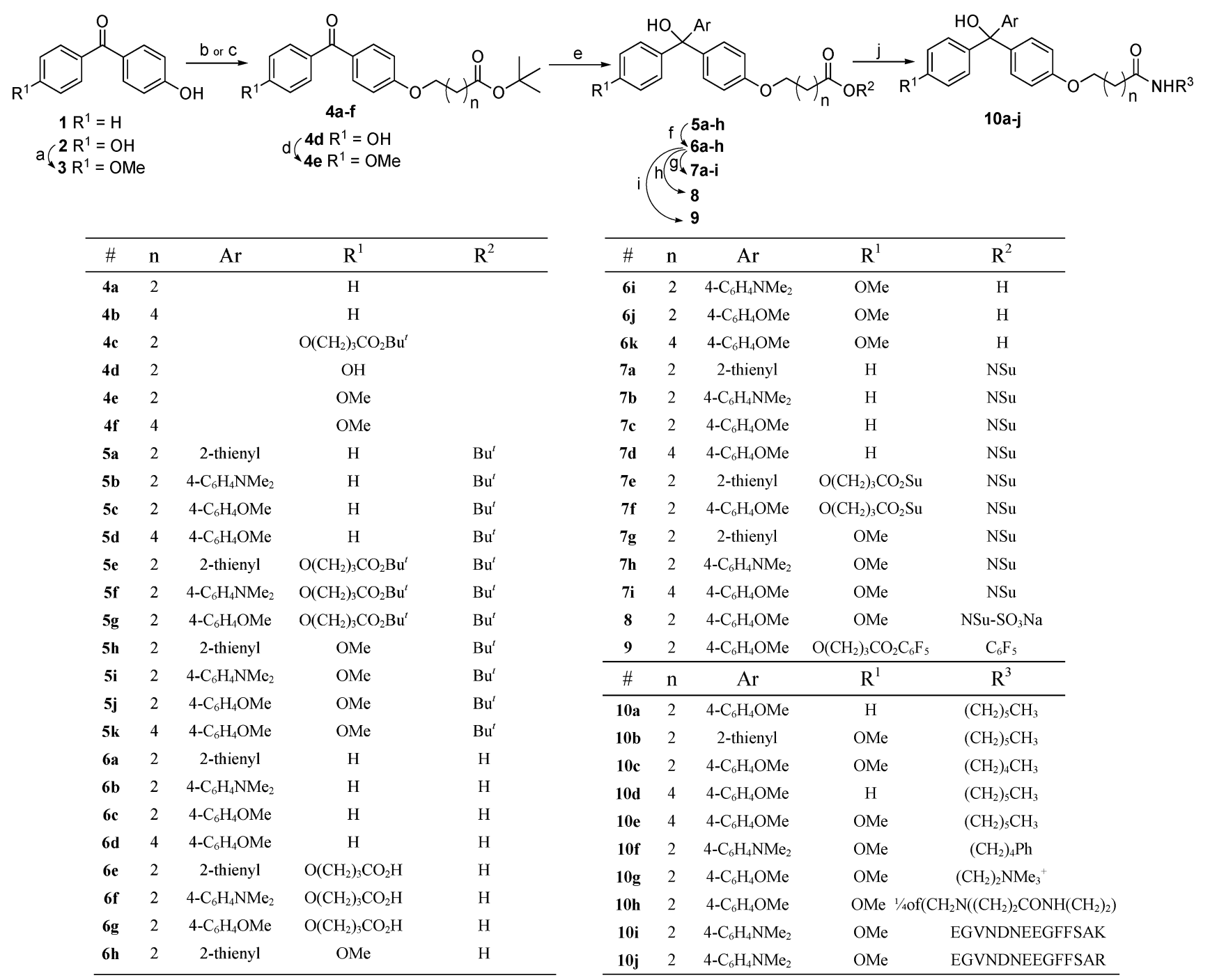

Scheme 2 Introduction of alkoxy linker into benzophenones and preparation of triarylmethanol derivatives. Reagents and conditions: a) MeI, NaH, DMF, rt; b) $\mathrm{Cl}\left(\mathrm{CH}_{2}\right)_{3} \mathrm{CO}_{2} \mathrm{Bu}^{t}$, MeONa, HMPA, $100{ }^{\circ} \mathrm{C}$; c) $\mathrm{Br}_{(}\left(\mathrm{CH}_{2}\right)_{5} \mathrm{CO}_{2} \mathrm{Bu}^{t}, \mathrm{~K}_{2} \mathrm{CO}_{3}$, acetone, rt; d) $\mathrm{MeI}, \mathrm{K}_{2} \mathrm{CO}_{3}$, acetone, rt; e) $\mathrm{ArMgBr}$, THF, rt; f) $\mathrm{CF}_{3} \mathrm{CO}_{2} \mathrm{H}, \mathrm{DCM}, \mathrm{rt}$; g) DSC, $\mathrm{Et}_{3} \mathrm{~N}, \mathrm{DCM}, \mathrm{rt}$; h) HONSu-SO${ }_{3} \mathrm{Na}, \mathrm{DCC}, \mathrm{DMF}$, rt; i) $\mathrm{C}_{6} \mathrm{~F}_{5} \mathrm{OH}, \mathrm{DCC}, \mathrm{EtOAc}, \mathrm{rt}$; j) R ${ }^{3} \mathrm{NH}_{2}, \mathrm{THF}, \mathrm{rt}$.

popular techniques dubbed ICAT and ITRAQ are often employed whereby proteomes or peptidomes are labelled with two thiolspecific or amine-specific reagents identical but for their isotopic composition. ${ }^{17}$ To make the trityl MT labelling platform compatible with this isotope-based quantification method, we prepared a series of compounds identical in structure but different in mass. A deuterium-based approach is easier to implement as one simply needs to reduce triple bonds with $\mathrm{D}_{2}$ to arrive at a set of compounds different from the hydrogen reduced ones by $4 \mathrm{Da}$. Unfortunately, deuterated compounds are eluted differently from hydrogenated ones on HPLC, making it difficult to follow LC-MS proteomics protocols. To obviate this problem, we used ${ }^{13} \mathrm{C}$ labelling when preparing ketone building blocks 23d for trityl assembly. Target compound $\mathbf{2 7} \mathbf{b}$, when used in combination with a non-labelled version 26c, gives a pair of chemically and structurally identical MTs with 4 Da mass difference. Importantly, this scheme allows one to prepare MTs with only one $\mathrm{R}^{1}$ group containing the heavier version of ethyl, giving rise to a series of 3 MTs with $2 \mathrm{Da}$ difference. This is useful if more than 2 conjugates need to be quantified by MS. Trityl chemistry permits for even more isotopically labelled alkyl groups to be introduced should the need arise. Importantly, unlike the ICAT reagents, the trityl MTs are "active" in that they not only serve as mass appendages to differentiate between analyte molecules, but also enhance the MS performance of the conjugates (vide infra, Fig. 8, 9). Work is now in progress to employ these trityl tags in quantitation of peptides by MS.

To be able to combine a xanthyl or a thioxanthyl moiety with an aryl block to which no side-arm could be (easily) attached, e.g. a pyreny ${ }^{16}$ residue, we developed an approach allowing for a linker to be connected to a (thio)xanthyl block. Synthesis of an alkyl functionalised xanthone trityl is shown on Scheme 5.

3-Hydroxy-6-methoxy-9H-xanthen-9-one (33) was converted into the phenol triflate in good yield. Our strategy to convert 

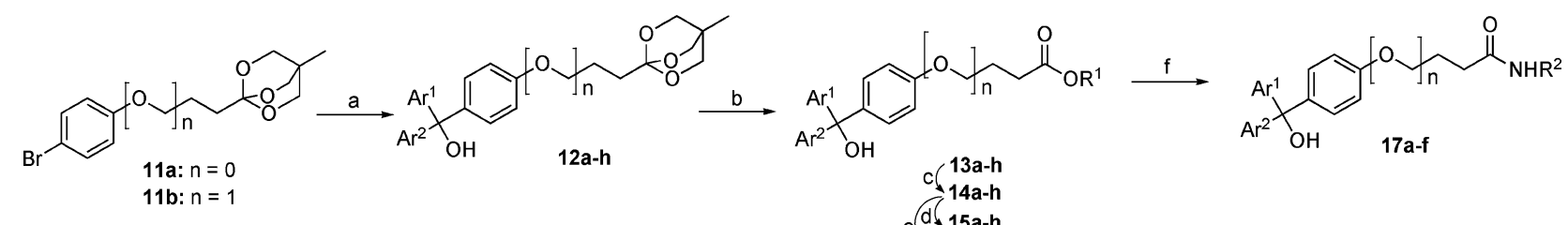

\begin{tabular}{|c|c|c|c|c|}
\hline \# & $\mathrm{n}$ & $\mathrm{Ar}^{1}$ & $\mathrm{Ar}^{2}$ & $\mathrm{R}^{1}$ \\
\hline $12 \mathrm{a}$ & 0 & 4- $\mathrm{C}_{6} \mathrm{H}_{4} \mathrm{OMe}$ & $\mathrm{C}_{6} \mathrm{H}_{4} \mathrm{OMe}$ & \\
\hline $12 \mathrm{~b}$ & 0 & & & \\
\hline $12 \mathrm{c}$ & 0 & $4-\mathrm{C}_{6} \mathrm{H}$ & $\mathrm{SMe}$ & \\
\hline $12 \mathrm{~d}$ & 0 & & & \\
\hline $12 \mathrm{e}$ & 0 & & & \\
\hline $12 \mathrm{f}$ & 0 & & & \\
\hline $12 \mathrm{~g}$ & 1 & 4- $\mathrm{C}_{6} \mathrm{H}_{4} \mathrm{OMe}$ & 4- $\mathrm{C}_{6} \mathrm{H}_{4} \mathrm{OMe}$ & \\
\hline $12 \mathrm{~h}$ & 1 & 4- $\mathrm{C}_{6} \mathrm{H}_{4} \mathrm{SMe}$ & 4- $\mathrm{C}_{6} \mathrm{H}_{4} \mathrm{SMe}$ & \\
\hline $13 \mathrm{a}$ & 0 & 4- $\mathrm{C}_{6} \mathrm{H}_{4} \mathrm{OMe}$ & 4- $\mathrm{C}_{6} \mathrm{H}_{4} \mathrm{OMe}$ & $\mathrm{CH}_{2} \mathrm{CMe}\left(\mathrm{CH}_{2} \mathrm{OH}\right)_{2}$ \\
\hline $13 b$ & 0 & & & $\mathrm{CH}_{2} \mathrm{CMe}\left(\mathrm{CH}_{2} \mathrm{OH}\right)_{2}$ \\
\hline $13 \mathrm{c}$ & 0 & $4-\mathrm{C}_{6} \mathrm{H}_{4}$ & $\mathrm{H}_{4} \mathrm{SMe}$ & $\mathrm{CH}_{2} \mathrm{CMe}\left(\mathrm{CH}_{2} \mathrm{OH}\right)_{2}$ \\
\hline $13 d$ & 0 & & & $\mathrm{CH}_{2} \mathrm{CMe}\left(\mathrm{CH}_{2} \mathrm{OH}\right)_{2}$ \\
\hline $13 \mathrm{e}$ & 0 & & & $\mathrm{CH}_{2} \mathrm{CMe}\left(\mathrm{CH}_{2} \mathrm{OH}\right)_{2}$ \\
\hline $13 f$ & 0 & & & $\mathrm{CH}_{2} \mathrm{CMe}\left(\mathrm{CH}_{2} \mathrm{OH}\right)_{2}$ \\
\hline $13 \mathrm{~g}$ & 1 & 4- $\mathrm{C}_{6} \mathrm{H}_{4} \mathrm{OMe}$ & 4- $\mathrm{C}_{6} \mathrm{H}_{4} \mathrm{OMe}$ & $\mathrm{CH}_{2} \mathrm{CMe}\left(\mathrm{CH}_{2} \mathrm{OH}\right)_{2}$ \\
\hline $13 \mathrm{~h}$ & 1 & 4- $\mathrm{C}_{6} \mathrm{H}_{4} \mathrm{SMe}$ & 4- $\mathrm{C}_{6} \mathrm{H}_{4} \mathrm{SMe}$ & $\mathrm{CH}_{2} \mathrm{CMe}\left(\mathrm{CH}_{2} \mathrm{OH}\right)_{2}$ \\
\hline $14 a$ & 0 & 4- $\mathrm{C}_{6} \mathrm{H}_{4} \mathrm{OMe}$ & $4-\mathrm{C}_{6} \mathrm{H}_{4} \mathrm{OMe}$ & $\mathrm{H}$ \\
\hline $14 \mathrm{~b}$ & 0 & & & $\mathrm{H}$ \\
\hline $14 \mathrm{c}$ & 0 & 4- $\mathrm{C}_{6} \mathrm{H}_{4} \mathrm{SMe}$ & 4- $\mathrm{C}_{6} \mathrm{H}_{4} \mathrm{SMe}$ & $\mathrm{H}$ \\
\hline
\end{tabular}

\begin{tabular}{|c|c|c|c|c|}
\hline$\#$ & $\mathrm{n}$ & $\mathrm{Ar}^{1}$ & $\mathrm{Ar}^{2}$ & $\mathrm{R}^{1}$ \\
\hline $14 d$ & 0 & & & $\mathrm{H}$ \\
\hline $14 \mathrm{e}$ & 0 & & & $\mathrm{H}$ \\
\hline $14 f$ & 0 & & & $\mathrm{H}$ \\
\hline $14 \mathrm{~g}$ & 1 & 4- $\mathrm{C}_{6} \mathrm{H}_{4} \mathrm{OMe}$ & $4-\mathrm{C}_{6} \mathrm{H}_{4} \mathrm{OMe}$ & $\mathrm{H}$ \\
\hline $14 \mathrm{~h}$ & 1 & $4-\mathrm{C}_{6} \mathrm{H}_{4} \mathrm{SMe}$ & 4- $\mathrm{C}_{6} \mathrm{H}_{4} \mathrm{SMe}$ & $\mathrm{H}$ \\
\hline $15 \mathbf{a}$ & 0 & $4-\mathrm{C}_{6} \mathrm{H}_{4} \mathrm{OMe}$ & $\mathrm{I}_{4} \mathrm{OMe}$ & NSu \\
\hline $15 b$ & 0 & & & $\mathrm{NSu}$ \\
\hline $15 \mathrm{c}$ & 0 & $4-\mathrm{C}_{6} \mathrm{H}_{4}$ & $\mathrm{I}_{4} \mathrm{SMe}$ & $\mathrm{NSu}$ \\
\hline 15d & 0 & & & NSu \\
\hline $15 \mathrm{e}$ & 0 & & & $\mathrm{NSu}$ \\
\hline $15 f$ & 0 & & & $\mathrm{NSu}$ \\
\hline $15 \mathrm{~g}$ & 1 & 4- $\mathrm{C}_{6} \mathrm{H}_{4} \mathrm{OMe}$ & 4- $\mathrm{C}_{6} \mathrm{H}_{4} \mathrm{OMe}$ & $\mathrm{NSu}$ \\
\hline $15 \mathrm{~h}$ & 1 & $4-\mathrm{C}_{6} \mathrm{H}_{4} \mathrm{SMe}$ & $4-\mathrm{C}_{6} \mathrm{H}_{4} \mathrm{SMe}$ & NSu \\
\hline $16 \mathbf{a}$ & 0 & $4-\mathrm{C}_{6} \mathrm{H}_{4} \mathrm{OMe}$ & 4- $\mathrm{C}_{6} \mathrm{H}_{4} \mathrm{OMe}$ & $\mathrm{NSu}-\mathrm{SO}_{3} \mathrm{Na}$ \\
\hline $16 \mathrm{~b}$ & 0 & 4- $\mathrm{C}_{6} \mathrm{H}_{4} \mathrm{SMe}$ & 4- $\mathrm{C}_{6} \mathrm{H}_{4} \mathrm{SMe}$ & $\mathrm{NSu}-\mathrm{SO}_{3} \mathrm{Na}$ \\
\hline$\#$ & $\mathrm{n}$ & $\mathrm{Ar}^{1}$ & $\mathrm{Ar}^{2}$ & $\mathrm{R}^{2}$ \\
\hline $17 \mathbf{a}$ & 0 & $4-\mathrm{C}_{6} \mathrm{H}_{4} \mathrm{OMe}$ & 4- $\mathrm{C}_{6} \mathrm{H}_{4} \mathrm{OMe}$ & $\left(\mathrm{CH}_{2}\right)_{4} \mathrm{CH}_{3}$ \\
\hline $17 \mathrm{~b}$ & 0 & 4- $\mathrm{C}_{6} \mathrm{H}_{4} \mathrm{SMe}$ & 4- $\mathrm{C}_{6} \mathrm{H}_{4} \mathrm{SMe}$ & $\left(\mathrm{CH}_{2}\right)_{4} \mathrm{CH}_{3}$ \\
\hline $17 \mathrm{c}$ & 0 & $4-\mathrm{C}_{6} \mathrm{H}_{4} \mathrm{OMe}$ & $4-\mathrm{C}_{6} \mathrm{H}_{4} \mathrm{OMe}$ & $1 / 2$ of $-\mathrm{CH}_{2} \mathrm{CH}_{2}-$ \\
\hline $17 d$ & 0 & $4-\mathrm{C}_{6} \mathrm{H}_{4} \mathrm{OMe}$ & 4- $\mathrm{C}_{6} \mathrm{H}_{4} \mathrm{OMe}$ & $\begin{array}{r}1 / 3 \text { of } \mathrm{C}_{6} \mathrm{H}_{3}-1,3,5- \\
\left(\mathrm{CONH}\left(\mathrm{CH}_{2}\right)_{3}\right)_{3}\end{array}$ \\
\hline $17 \mathrm{e}$ & 0 & $4-\mathrm{C}_{6} \mathrm{H}_{4} \mathrm{OMe}$ & $4-\mathrm{C}_{6} \mathrm{H}_{4} \mathrm{OMe}$ & EGVNDNEEGFFSAK \\
\hline $17 f$ & 0 & 4- $\mathrm{C}_{6} \mathrm{H}_{4} \mathrm{OMe}$ & 4- $\mathrm{C}_{6} \mathrm{H}_{4} \mathrm{OMe}$ & EGVNDNEEGFFSAR \\
\hline
\end{tabular}

Scheme 3 Alkyl or alkoxy linker on Grignard reagent: preparation of triarylmethanol derivatives. Reagents and conditions: a) 1) BuLi, THF, -70 ${ }^{\circ} \mathrm{C}, 2$ ) $\mathrm{Ar}^{1} \mathrm{COAr}^{2}$, THF, $-40{ }^{\circ} \mathrm{C}$; b) $\mathrm{CF}_{3} \mathrm{CO}_{2} \mathrm{H}, \mathrm{H}_{2} \mathrm{O}$, THF; c) 1) $\mathrm{NaOH}, \mathrm{EtOH}, \mathrm{H}_{2} \mathrm{O}$; 2) $\mathrm{H}^{+}$; d) DSC, $\mathrm{Et}_{3} \mathrm{~N}, \mathrm{DCM}, \mathrm{rt}$; e) $\mathrm{HONSu}_{3} \mathrm{SO} \mathrm{Na}_{3}, \mathrm{DCC}, \mathrm{DMF}, \mathrm{rt}$; f) $\mathrm{R}^{2} \mathrm{NH}_{2}$, THF, rt.

the triflate 34 into 35 via a Sonagashira palladium cross-coupling reaction with tert-butyl hex-5-ynoate proceeded as anticipated, allowing a facile way of introducing the linker side arm. Grignard addition of 4-methoxyphenyl magnesium bromide to compound 35 yielded tritanol 36, and further synthetic steps finally gave the desired compounds $\mathbf{4 0}$. Hydrogenation of compound 38 was triple bond specific and did not affect the trityl carbinol.

Maleimide is a convenient thiol-reactive function for the labelling of cysteine-containing proteins and peptides. In the preparation of maleimide derivatives of tritanols (Schemes 6 and 7) a hydroxyl group was used as a precursor for a maleimide. Tetrahydropyranyl protection was used for the $\mathrm{OH}$ group. Bromoaryl precursor 41 was lithiated and then reacted with 4,4'dimethoxybenzophenone. The acidic removal of the Thp group gives trityl methyl ether 43. This reacted with maleimide under Mitsunobu conditions. Toluene was found to be the solvent of choice for this reaction. The careful removal of Me group gives tritanol 45 (Scheme 6).

The maleimide derivative of trimethoxytritanol (Scheme 7) was prepared using synthetic strategies shown on Schemes 4 and 6 .

We have thus prepared a variety of trityl blocks with different $\mathrm{pK}_{\mathrm{R}+}$ values bearing an assortment of reactive groups (oxysuccinimide, sulfo-oxysuccinimide, and pentafluorophenyl esters or maleimido) for testing in conjugation reactions.

\section{Charge state of trityl clusters}

We anticipated that conjugation of mass-tags with polyfunctional molecules such as peptides could result in multiple labelling of, say, several amino groups. To investigate the effect of mass-tagging, including multiple attachments of mass-tags (possibly resulting in formation of multiply charged ions), on MS behaviour, we 
<smiles>[R10]Oc1ccc(C(=O)c2ccc(O[R10])c(C#CCCCC(=O)OC(C)(C)C)c2)cc1</smiles>

a 18: $R^{1}=\mathrm{Me}$

22a-c

19: $R^{1}=H$

c b. 20: $R^{1}=E t$

21: $R^{1}=B n$<smiles>[R10]Oc1ccc(C(=O)c2ccc(O[R10])c(CCCCCC(=O)OC(C)(C)C(C)(C)C)c2)cc1</smiles>

23a-d

$f\left(\begin{array}{l}23 \mathrm{c} \\ 23 \mathrm{~d}\end{array}\right.$

h. 24a-d

i 25a-d<smiles>[R]NC(=O)CCCCCc1cc(C(O)([Al])c2ccc([R20])cc2)ccc1O[R]</smiles>

27a-b

28a-j<smiles>[R1]NC(=O)CCCC#Cc1cc(C(O)([Al])c2ccc(O[R2])cc2)ccc1O[R1]</smiles>

\begin{tabular}{|c|c|c|c|}
\hline$\#$ & $\mathrm{R}^{1}$ & $\mathrm{Ar}$ & $\mathrm{R}^{2}$ \\
\hline $22 a$ & $\mathrm{Me}$ & & \\
\hline $22 b$ & Et & & \\
\hline $22 c$ & $\mathrm{Bn}$ & & \\
\hline $23 a$ & $\mathrm{Me}$ & & \\
\hline $23 b$ & Et & & \\
\hline $23 c$ & $\mathrm{H}$ & & \\
\hline 23d & {$\left[{ }^{13} \mathrm{C}\right] \mathrm{Et}$} & & \\
\hline $24 a$ & $\mathrm{Me}$ & 4- $\mathrm{C}_{6} \mathrm{H}_{4} \mathrm{OMe}$ & $\mathrm{Bu}^{t}$ \\
\hline $24 b$ & $\mathrm{Me}$ & $4-\mathrm{C}_{6} \mathrm{H}_{4} \mathrm{NMe}_{2}$ & $\mathrm{Bu}^{t}$ \\
\hline $24 c$ & Et & 4- $\mathrm{C}_{6} \mathrm{H}_{4} \mathrm{OMe}$ & $\mathrm{Bu}^{t}$ \\
\hline $24 d$ & {$\left[{ }^{13} \mathrm{C}\right] \mathrm{Et}$} & 4- $\mathrm{C}_{6} \mathrm{H}_{4} \mathrm{OMe}$ & $\mathrm{Bu}^{t}$ \\
\hline $25 a$ & $\mathrm{Me}$ & 4- $\mathrm{C}_{6} \mathrm{H}_{4} \mathrm{OMe}$ & $\mathrm{H}$ \\
\hline $25 b$ & $\mathrm{Me}$ & $4-\mathrm{C}_{6} \mathrm{H}_{4} \mathrm{NMe}_{2}$ & $\mathrm{H}$ \\
\hline $25 c$ & Et & 4- $\mathrm{C}_{6} \mathrm{H}_{4} \mathrm{OMe}$ & $\mathrm{H}$ \\
\hline 25d & {$\left[{ }^{13} \mathrm{C}\right] \mathrm{Et}$} & 4- $\mathrm{C}_{6} \mathrm{H}_{4} \mathrm{OMe}$ & $\mathrm{H}$ \\
\hline $26 a$ & $\mathrm{Me}$ & 4- $\mathrm{C}_{6} \mathrm{H}_{4} \mathrm{OMe}$ & $\mathrm{NSu}$ \\
\hline $26 \mathrm{~b}$ & $\mathrm{Me}$ & $4-\mathrm{C}_{6} \mathrm{H}_{4} \mathrm{NMe}_{2}$ & $\mathrm{NSu}$ \\
\hline $26 c$ & Et & 4- $\mathrm{C}_{6} \mathrm{H}_{4} \mathrm{OMe}$ & $\mathrm{NSu}$ \\
\hline $27 a$ & $\mathrm{Me}$ & 4- $\mathrm{C}_{6} \mathrm{H}_{4} \mathrm{OMe}$ & $\mathrm{NSu}-\mathrm{SO}_{3} \mathrm{Na}$ \\
\hline $27 b$ & {$\left[{ }^{13} \mathrm{C}\right] \mathrm{Et}$} & 4- $\mathrm{C}_{6} \mathrm{H}_{4} \mathrm{OMe}$ & $\mathrm{NSu}-\mathrm{SO}_{3} \mathrm{Na}$ \\
\hline
\end{tabular}

\begin{tabular}{cccc}
\hline$\#$ & $\mathrm{R}^{1}$ & $\mathrm{Ar}$ & $\mathrm{R}^{3}$ \\
\hline $\mathbf{2 8 a}$ & $\mathrm{Me}$ & $4-\mathrm{C}_{6} \mathrm{H}_{4} \mathrm{OMe}$ & $\left(\mathrm{CH}_{2}\right)_{3} \mathrm{CH}_{3}$ \\
$\mathbf{2 8 b}$ & $\mathrm{Me}$ & $4-\mathrm{C}_{6} \mathrm{H}_{4} \mathrm{OMe}$ & $\left(\mathrm{CH}_{2}\right)_{4} \mathrm{CH}_{3}$ \\
$\mathbf{2 8 c}$ & $\mathrm{Me}$ & $4-\mathrm{C}_{6} \mathrm{H}_{4} \mathrm{OMe}$ & $\left(\mathrm{CH}_{2}\right)_{5} \mathrm{CH}_{3}$ \\
$\mathbf{2 8 d}$ & $\mathrm{Me}$ & $4-\mathrm{C}_{6} \mathrm{H}_{4} \mathrm{OMe}$ & $\left(\mathrm{CH}_{2}\right)_{7} \mathrm{CH}_{3}$ \\
$\mathbf{2 8 e}$ & $\mathrm{Me}$ & $4-\mathrm{C}_{6} \mathrm{H}_{4} \mathrm{OMe}$ & $\left(\mathrm{CH}_{2}\right)_{8} \mathrm{CH}_{3}$ \\
$\mathbf{2 8 f}$ & $\mathrm{Me}$ & $4-\mathrm{C}_{6} \mathrm{H}_{4} \mathrm{OMe}$ & $\left(\mathrm{CH}_{2}\right)_{9} \mathrm{CH}_{3}$ \\
$\mathbf{2 8 g}$ & $\mathrm{Me}$ & $4-\mathrm{C}_{6} \mathrm{H}_{4} \mathrm{OMe}$ & $\left(\mathrm{CH}_{2}\right)_{2} \mathrm{Ph}$ \\
$\mathbf{2 8 h}$ & $\mathrm{Me}$ & $4-\mathrm{C}_{6} \mathrm{H}_{4} \mathrm{OMe}$ & $\left(\mathrm{CH}_{2}\right)_{3} \mathrm{Ph}$ \\
$\mathbf{2 8 i}$ & $\mathrm{Me}$ & $4-\mathrm{C}_{6} \mathrm{H}_{4} \mathrm{OMe}$ & $\mathrm{EGVNDNEEGFFSAK}$ \\
$\mathbf{2 8 j}$ & $\mathrm{Me}$ & $4-\mathrm{C}_{6} \mathrm{H}_{4} \mathrm{OMe}$ & $\mathrm{EGVNDNEEGFFSAR}$ \\
\hline$\#$ & $\mathrm{R}{ }^{1}$ & $\mathrm{Ar}$ & $\mathrm{R}^{2}$ \\
\hline $\mathbf{2 9}$ & $\mathrm{Me}$ & $4-\mathrm{C}_{6} \mathrm{H}_{4} \mathrm{OMe}$ & $\mathrm{Bu}^{t}$ \\
$\mathbf{3 0}$ & $\mathrm{Me}$ & $4-\mathrm{C}_{6} \mathrm{H}_{4} \mathrm{OMe}$ & $\mathrm{H}$ \\
$\mathbf{3 1}$ & $\mathrm{Me}$ & $4-\mathrm{C}_{6} \mathrm{H}_{4} \mathrm{OMe}$ & $\mathrm{NSu}$ \\
\hline$\#$ & $\mathrm{R}$ & $\mathrm{Ar}$ & $\mathrm{R}^{3}$ \\
\hline 32a & $\mathrm{Me}$ & $4-\mathrm{C}_{6} \mathrm{H}_{4} \mathrm{OMe}$ & $\left(\mathrm{CH}_{2}\right)_{5} \mathrm{CH}_{3}$ \\
\hline
\end{tabular}

Scheme 4 Introduction of alkyl linker into benzophenone and further conversion into triarylmethanol derivatives. Reagents and conditions: a) BBr ${ }_{3}$,

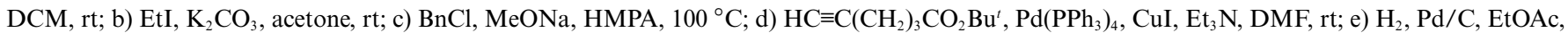
rt; f) $\left[{ }^{13} \mathrm{C}\right] \mathrm{EtOH}, \mathrm{DEAD}, \mathrm{Ph}_{3} \mathrm{P}$, THF, rt; g) ArMgBr, THF, rt; h) $\mathrm{CF}_{3} \mathrm{CO}_{2} \mathrm{H}, \mathrm{DCM}, \mathrm{rt}$; i) DSC, Et ${ }_{3} \mathrm{~N}, \mathrm{DCM}, \mathrm{rt}$; j) HONSu-SO $\mathrm{Ha}, \mathrm{DCC}, \mathrm{DMF}, \mathrm{rt}$; k) $\mathrm{R}^{3} \mathrm{NH}_{2}$, THF, rt.

prepared several model compounds by combining several tags together (Chart 1). The first conjugate, $10 \mathrm{~g}$, contained a trityl and a positively charged quaternary ammonium moiety. The MS analysis of this compound (Fig. 2) revealed only monocharged species: at $507 \mathrm{Da}$ (loss of $\mathrm{Cl}$ ) and at $490 \mathrm{Da}$ (loss of both $\mathrm{Cl}$ and $\mathrm{OH}$ moieties). No molecular ion (542 Da), or its adducts, or any double charged species were detected. Importantly, 525 Da peak $\left([\mathrm{MI}-\mathrm{OH}]^{+}\right)$was not detected either, neither with nor without (data not shown) matrix. This indicates that the trityl residue, upon losing the hydroxyl, exists apparently in a radical form.

Two trityl mass-tags were linked together by coupling NHS ester 15a with diaminoethane. The resulting compound $\mathbf{1 7} \mathbf{c}$ ionised well 


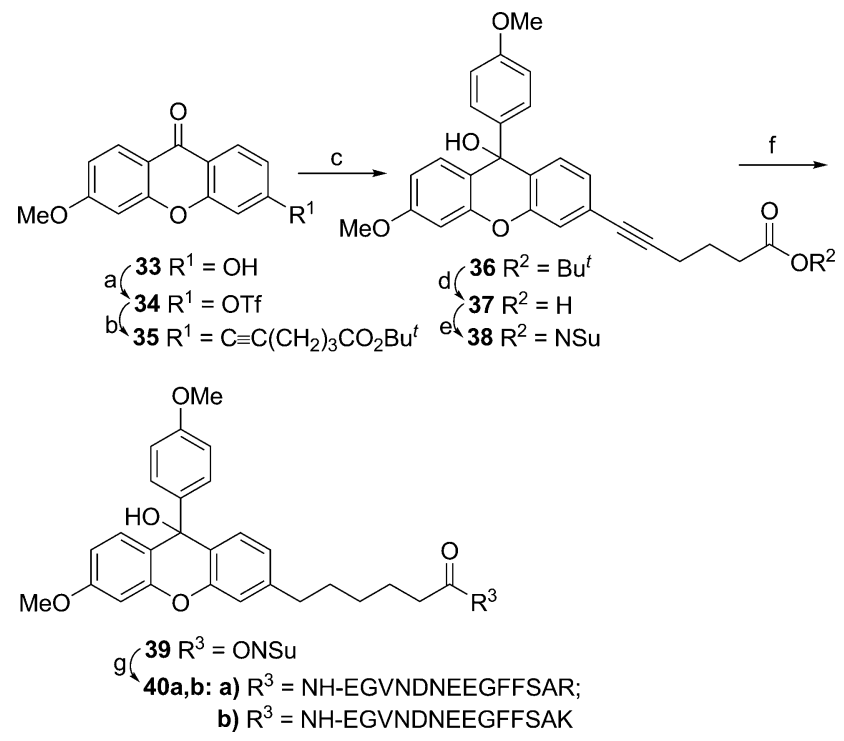

Scheme 5 Introduction of alkyl linker into xanthone and further conversion into triarylmethanol derivatives. Reagents and conditions: a) $\mathrm{Tf}_{2} \mathrm{O}$, DIEA, DCM, rt; b) $\mathrm{HC} \equiv \mathrm{C}\left(\mathrm{CH}_{2}\right)_{3} \mathrm{CO}_{2} \mathrm{Bu}^{t}, \mathrm{Pd}\left(\mathrm{PPh}_{3}\right)_{4}, \mathrm{CuI}, \mathrm{Et}_{3} \mathrm{~N}, \mathrm{DMF}$, rt; c) $\mathrm{ArMgBr}$, THF, rt; d) $\mathrm{CF}_{3} \mathrm{CO}_{2} \mathrm{H}, \mathrm{DCM}$, rt; e) DSC, $\mathrm{Et}_{3} \mathrm{~N}, \mathrm{DCM}$, rt; f) $\mathrm{H}_{2}, \mathrm{Pd} / \mathrm{C}$, EtOAc, rt; g) $\mathrm{R}^{3} \mathrm{NH}_{2}$, THF, rt.

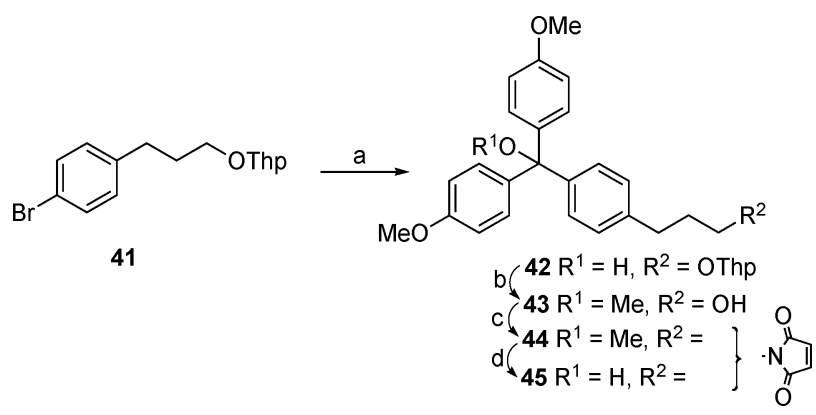

Scheme 6 Preparation of dimethoxytritanol based maleimide reagent. Reagents and conditions: a) 1) $\mathrm{BuLi}, \mathrm{THF},-70{ }^{\circ} \mathrm{C}, 2$ ) $\mathrm{MeOC}_{6} \mathrm{H}_{4} \mathrm{COC}_{6} \mathrm{H}_{4} \mathrm{OMe}$, THF, $-40{ }^{\circ} \mathrm{C}$; b) $\mathrm{CF}_{3} \mathrm{CO}_{2} \mathrm{H}$ (cat.), $\mathrm{MeOH}$; c) maleimide, DEAD, $\mathrm{Ph}_{3} \mathrm{P}$, toluene; d) $\mathrm{CF}_{3} \mathrm{CO}_{2} \mathrm{H}, \mathrm{H}_{2} \mathrm{O}$.

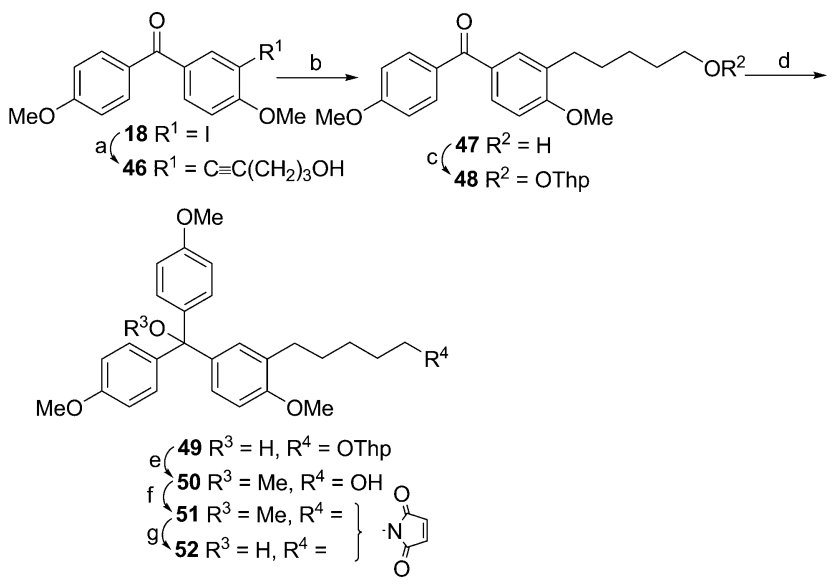

Scheme 7 Preparation of trimethoxytritanol based maleimide reagent. Reagents and conditions: a) $\mathrm{HC} \equiv \mathrm{C}\left(\mathrm{CH}_{2}\right)_{3} \mathrm{OH}, \mathrm{Pd}\left(\mathrm{PPh}_{3}\right)_{4}, \mathrm{CuI}, \mathrm{Et}_{3} \mathrm{~N}, \mathrm{DMF}$, rt; b) $\mathrm{H}_{2}, \mathrm{Pd} / \mathrm{C}$, EtOAc, rt; c) DHP, $\mathrm{H}^{+}$, DCM; d) $\mathrm{MeOC}_{6} \mathrm{H}_{4} \mathrm{MgBr}$, THF, rt; e) $\mathrm{CF}_{3} \mathrm{CO}_{2} \mathrm{H}$ (cat.), $\mathrm{MeOH}$; f) maleimide, DEAD, $\mathrm{Ph}_{3} \mathrm{P}$, toluene; g) $\mathrm{CF}_{3} \mathrm{CO}_{2} \mathrm{H}, \mathrm{H}_{2} \mathrm{O}$.

without matrix, producing strong peaks of roughly equal intensity at $791 \mathrm{Da}\left([\mathrm{MI}-\mathrm{OH}]^{+}\right)$and $774 \mathrm{Da}\left([\mathrm{MI}-2 \mathrm{OH}]^{+}\right)$ and no doubly charged species (Fig. 3). Since both hydroxyls are missing and the analyte desorbs as a monocharged ion, once again the suggestion regarding the state of the second trityl residue is that it is in a form of a radical.

A cluster of three tritanols linked together 17d was prepared using trimesic acid as a core molecule. In all cases, only a singly charged peak was detected (Fig. 4A), although these di- and tritritanols were successively losing all the $\mathrm{OH}$ groups (1483 Da, $[\mathrm{MI}-\mathrm{OH}]^{+} ; 1467 \mathrm{Da},[\mathrm{MI}-2 \mathrm{OH}]^{+} ; 1450 \mathrm{Da},[\mathrm{MI}-3 \mathrm{OH}]^{+}$; Fig. 4B).

In all of the above-described clusters, the trityl moieties are attached to the core through linkers flexible enough so that some conformations may allow for direct contact between trityl residues, decreasing the chance for several positive charges to co-exist in one molecule. To investigate this effect, as well as to further increase the number of trityls in a cluster, we have synthesised two more trityl blocks, one of which was flexible (10h) and another one not (56), linking four trityls through stiff arms (Scheme 8).

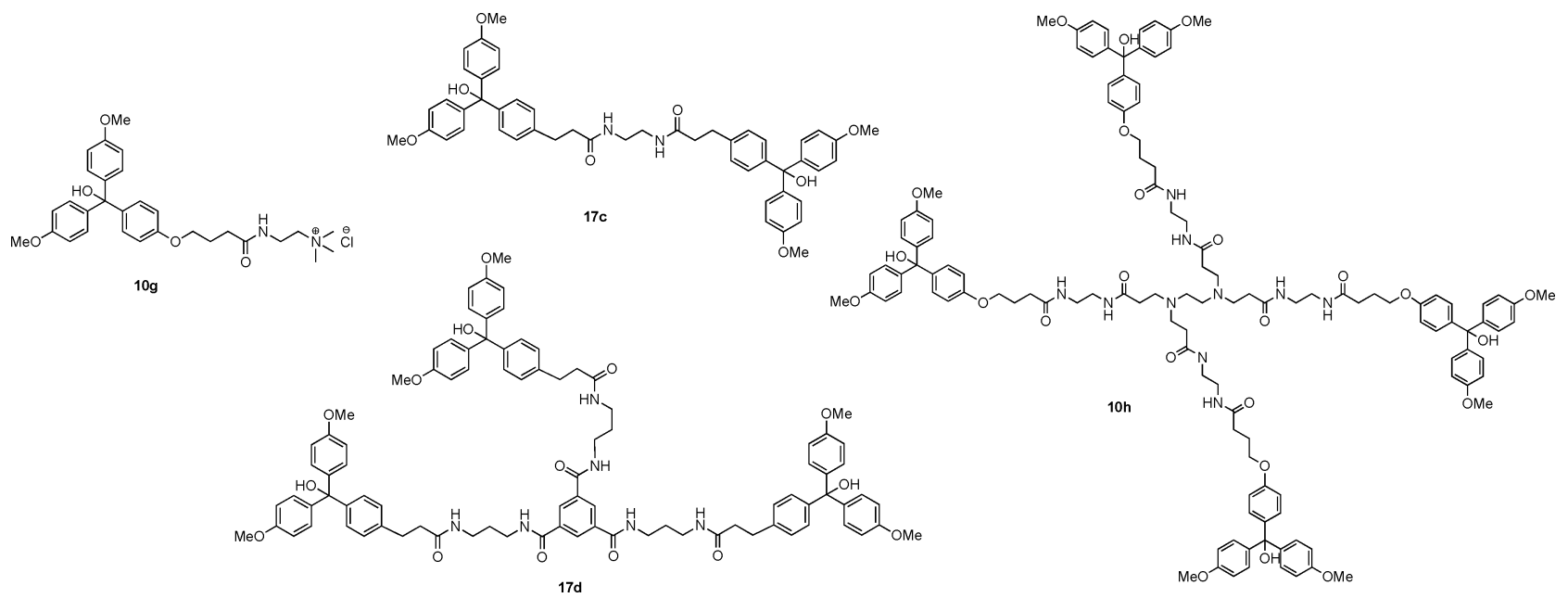

Chart 1 Structures of model compounds. 


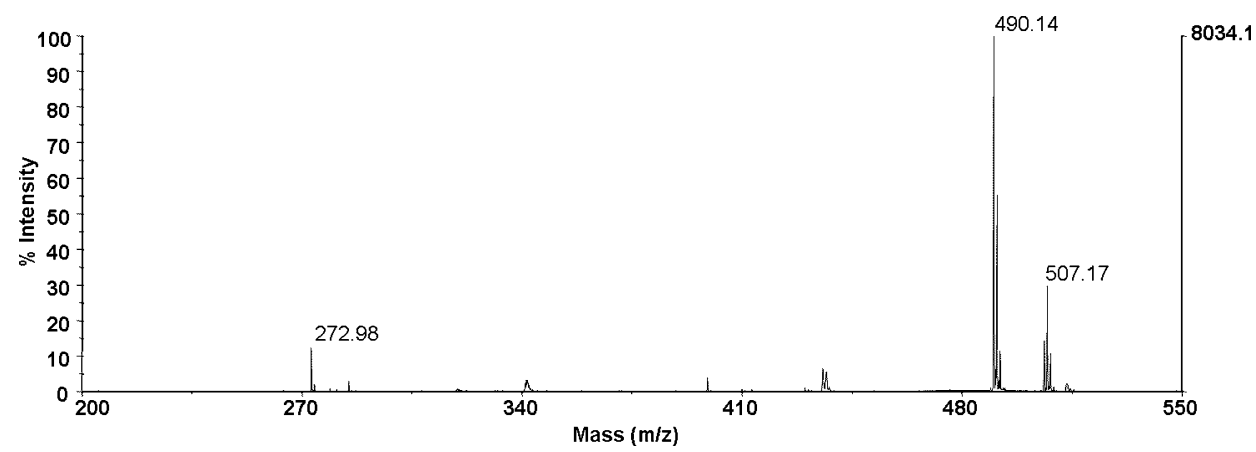

Fig. 2 MALDI-TOF analysis of compound $10 \mathrm{~g}$ (matrix: $0.5 \mathrm{~mm}^{3}$ of $20 \mathrm{mg} / \mathrm{cm}^{3}$ DHB was mixed with $0.5 \mathrm{~mm}^{3}$ of $1 \mathrm{mg} / \mathrm{cm}^{3} \mathrm{sample}$ ). No doubly charged species detected.

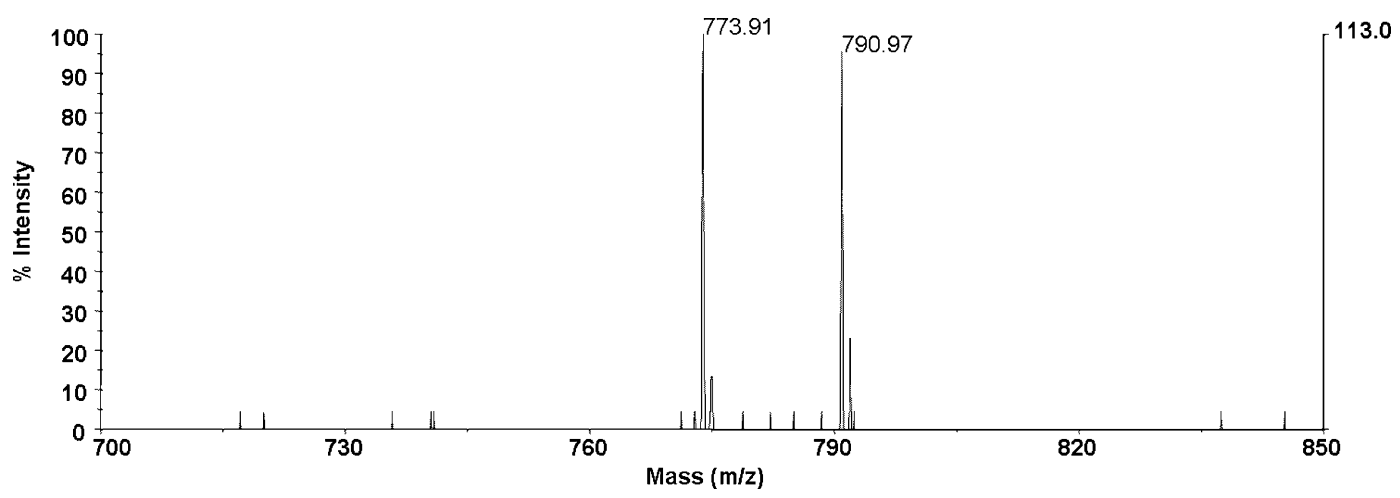

Fig. 3 LDI-TOF analysis of compound 17c. No doubly charged species or molecular ion were detected.
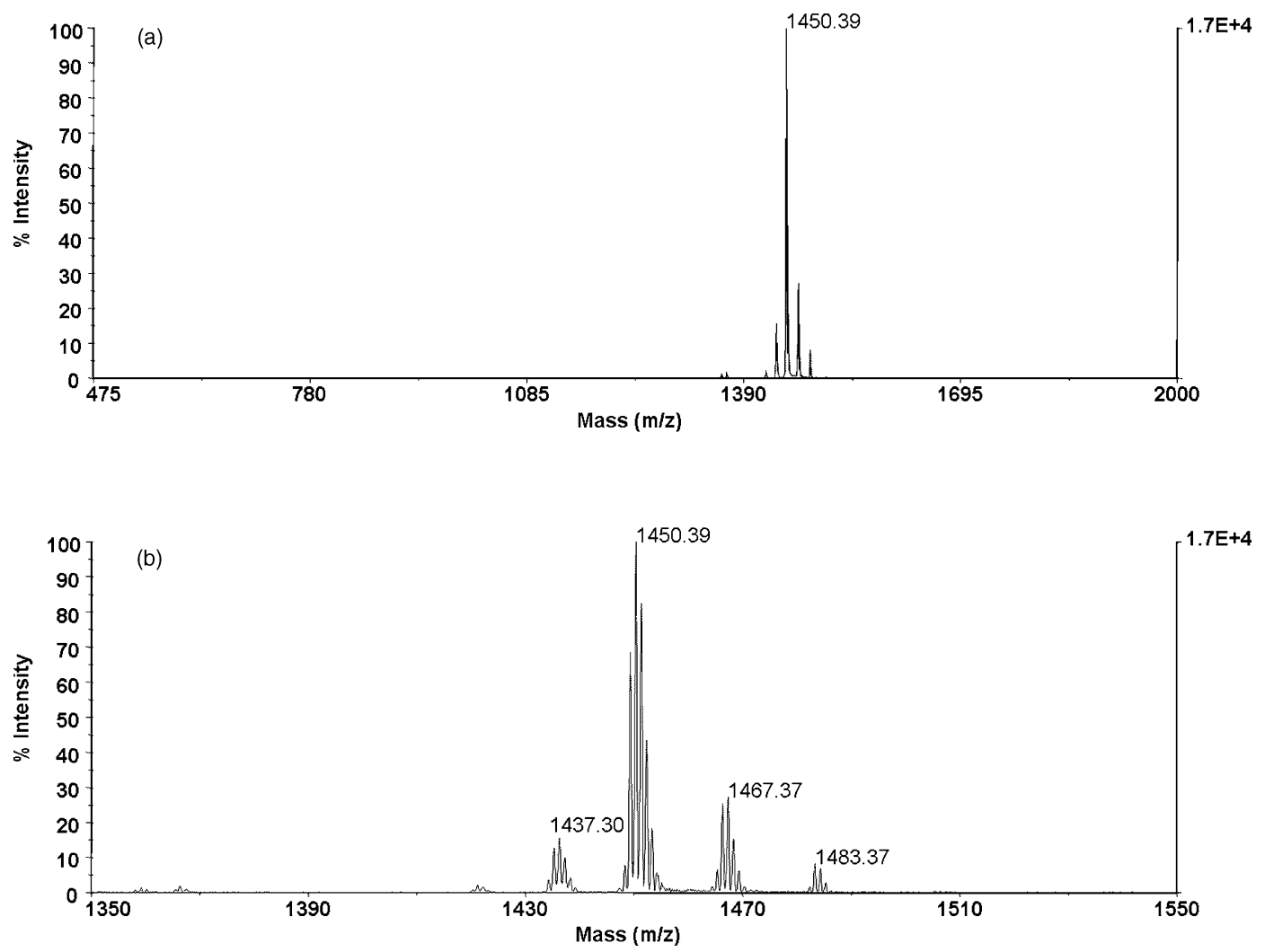

Fig. 4 MALDI-TOF analysis of compound 17d (matrix: $0.5 \mathrm{~mm}^{3}$ of $20 \mathrm{mg} / \mathrm{cm}^{3}$ DHB was mixed with $0.5 \mathrm{~mm}^{3} \mathrm{of} 1 \mathrm{mg} / \mathrm{cm}^{3} \mathrm{sample}$ ) No doubly/triply charged species or molecular ion were detected. The $1437 \mathrm{Da}$ peak is $[\mathrm{MI}-2 \mathrm{OH}-\mathrm{OMe}]^{+}$. 


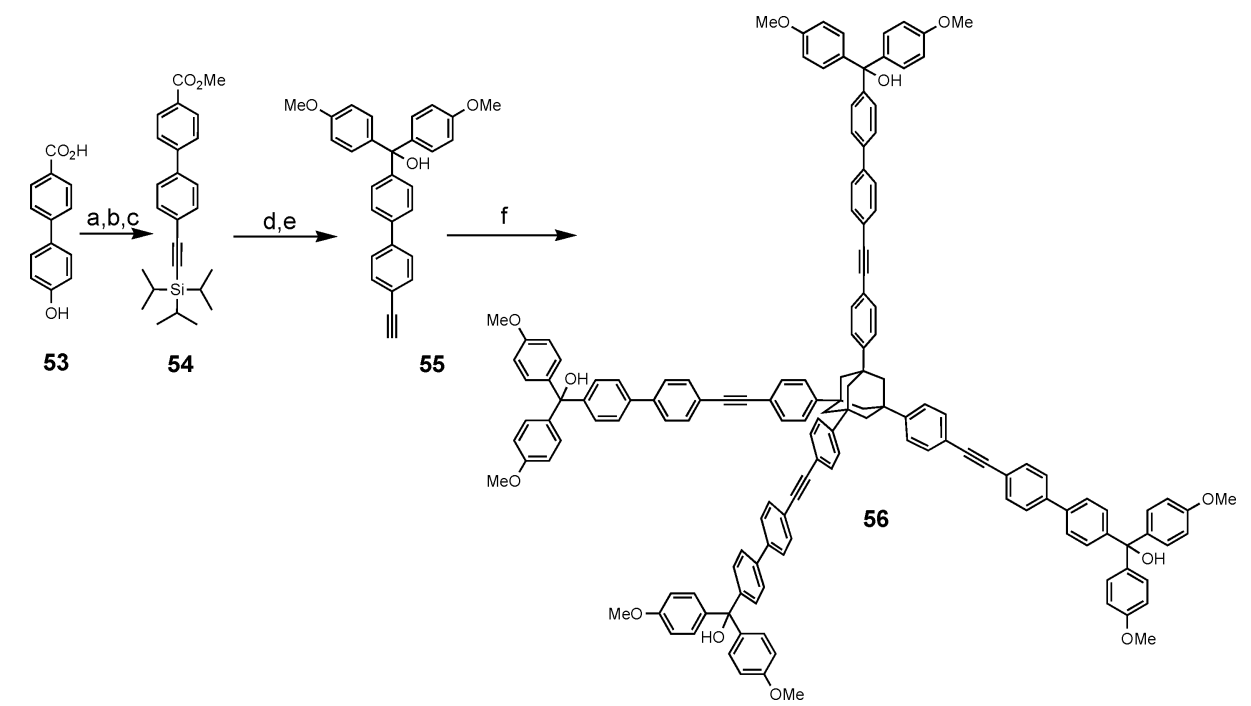

Scheme 8 Synthesis of a stiff cluster bearing four trityls. Reagents and conditions: a) $\left.\left.\left.\mathrm{SOCl}_{2}, \mathrm{MeOH}, \mathrm{rt} ; \mathrm{b}\right) \mathrm{Tf} \mathrm{O}_{2} \mathrm{O}, \mathrm{Py},-2{ }^{\circ} \mathrm{C} ; \mathrm{c}\right) \mathrm{HC} \equiv \mathrm{CSiPr}{ }_{3}, \mathrm{Pd}_{(\mathrm{PPh}}\right)_{4}$, $\mathrm{CuI}, \mathrm{Et}_{3} \mathrm{~N}, \mathrm{DMF}$, rt; d) 4-MeOC $\mathrm{H}_{4} \mathrm{MgBr}$, THF, reflux $3 \mathrm{~h}$; e) $\mathrm{Bu}_{4} \mathrm{NF}$, THF, rt; f) 1,3,5,7-tetra(4-iodophenyl)adamantane, $\mathrm{Pd}\left(\mathrm{PPh}_{3}\right)_{4}, \mathrm{CuI}, \mathrm{Et}_{3} \mathrm{~N}$, DMF, rt.

Once again, for both structures only a singly charged ion was detected, although the spectrum showed the consecutive loss of one, two, three and all four hydroxyls $\left(2117 \mathrm{Da},[\mathrm{MI}-\mathrm{OH}]^{+} ; 2100\right.$ $\mathrm{Da},[\mathrm{MI}-2 \mathrm{OH}]^{+} ; 2083 \mathrm{Da},[\mathrm{MI}-3 \mathrm{OH}]^{+} ; 2065 \mathrm{Da},[\mathrm{MI}-4 \mathrm{OH}]^{+}$; Fig. 5; and $2097 \mathrm{Da},[\mathrm{MI}-\mathrm{OH}]^{+} ; 2080 \mathrm{Da},[\mathrm{MI}-2 \mathrm{OH}]^{+} ; 2064$ $\mathrm{Da},[\mathrm{MI}-3 \mathrm{OH}]^{+}$; and $2047 \mathrm{Da},[\mathrm{MI}-4 \mathrm{OH}]^{+}$; Fig. 6).
This shows no difference in the charge state and the amount of hydroxyls lost between flexible and stiff or non flexible variants. Three different types of trityl moieties were used for these experiments, $(\mathbf{8}, \mathbf{1 5 a}, \mathbf{5 5})$, all with different $\mathrm{pK}_{\mathrm{R}+}$ values, thus ruling out the possible effect of the nature of trityls or the direct contacts of trityls within a molecule on its charge state.

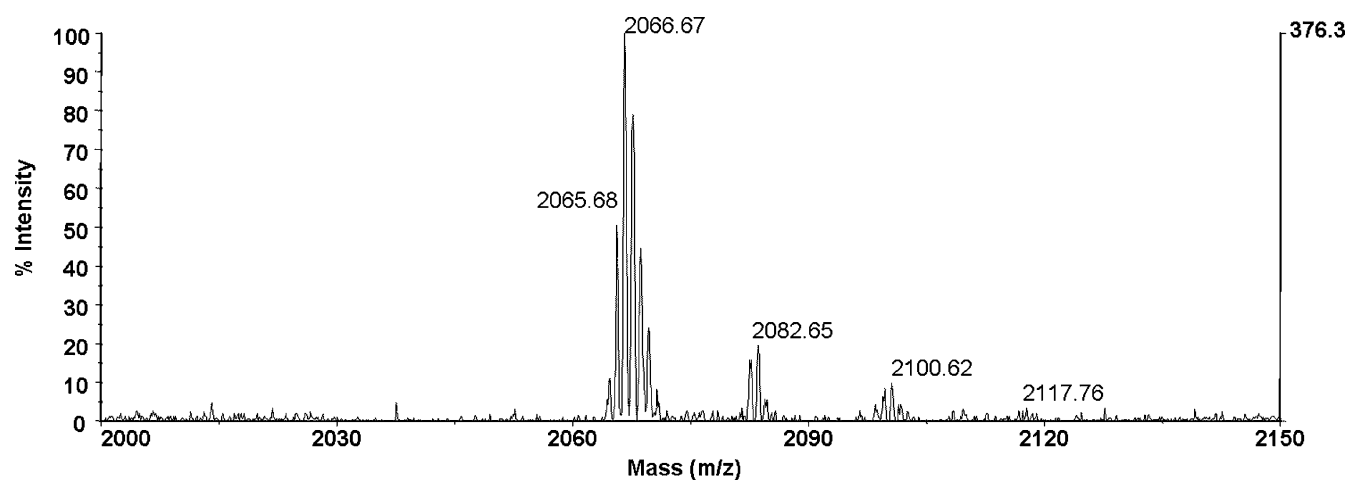

Fig. 5 MALDI-TOF analysis of compound 10h (matrix: $0.5 \mathrm{~mm}^{3}$ of $20 \mathrm{mg} / \mathrm{cm}^{3}$ DHB was mixed with $0.5 \mathrm{~mm} \mathrm{of}^{3} 1 \mathrm{mg} / \mathrm{cm}^{3} \mathrm{sample}$ ). No doubly/triply/quadruply charged species or MI were detected.

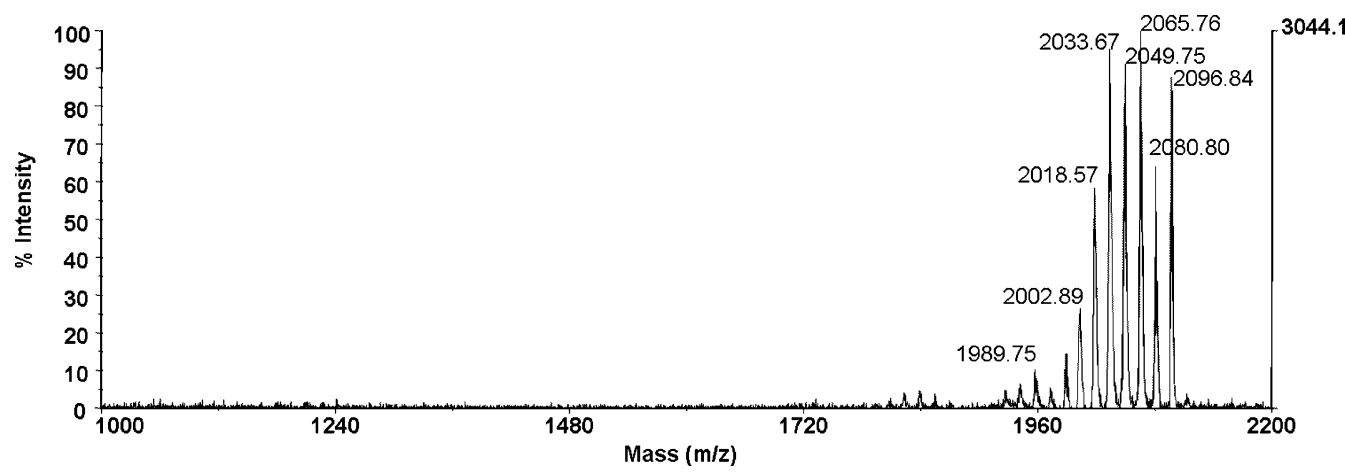

Fig. 6 MALDI-TOF analysis of compound 56 (matrix: $0.5 \mathrm{~mm}^{3}$ of $20 \mathrm{mg} / \mathrm{cm}^{3}$ DHB was mixed with $0.5 \mathrm{~mm} \mathrm{~m}^{3}$ of $1 \mathrm{mg} / \mathrm{cm}^{3} \mathrm{sample}$ ). No doubly/triply/quadruply charged species or MI were detected. Peaks below 2050 Da correspond to species with cleaved methoxyl groups. 
It is known from the literature that polytrityl cations exist and are stable. ${ }^{18}$ It is also known that, albeit to a lesser extent compared to ESI-MS, multiply charged cations can be detected by MALDITOF. ${ }^{19}$

On the other hand, it has been previously reported that peptides derivatised with two quaternary ammonium tags form only singly (and not doubly) charged ions in MALDI-TOF, ${ }^{9 a}$ a finding earlier reported for model "double-quads". ${ }^{20}$ As multiply charged species are a nuisance that complicates the interpretation of the MS data, we were relieved to find out that our tags should not cause this problem, and moved on to test them with model peptides.

\section{MS studies of peptide conjugates}

We tested some of the trityl mass-tags for their ability to enhance the ionisation and desorption properties of peptides in MALDITOF. Typically, a bottom-up proteomics approach consists of digesting a set of proteins with trypsin, that yields peptides Cterminated with Lys or Arg, which are subsequently analysed by MS. These two types are known to ionise differently in conditions of MALDI-TOF: Arg-terminated peptides are detected on average 6 times better. ${ }^{21}$ But even within each of the two fractions the intensities differ, so that only some of peptides produced from a protein by an enzymatic digest are detectable by a MALDITOF technique, despite the fact that the peptides are present in equimolar amounts. In other words, there is a need to improve the ionisation ability of all peptides, if not making the intensities more uniform.

We have therefore investigated the MS enhancement by synthesising two sets of model peptides using a solid-phase approach. Glu-Fib peptide (EGVNDNEEGFFSAR), and its C-end Lys- terminated analog (EGVNDNEEGFFSAK) were synthesised using Fmoc chemistry. ${ }^{22}$ The Fmoc groups were removed, and the Arg and Lys resin batches were then split into fractions and treated with NHS-activated trityl tags $\left(2-5 \mathrm{~cm}^{3}\right.$ of $0.05 \mathrm{M}$ solutions in pyridine) for 15-20 minutes. The solid-bound conjugates were then cleaved, deprotected and purified to about $90 \%$ purity by ionexchange HPLC using standard protocols, yielding 4-10 mg of each conjugate as well as the nonlabelled control. ${ }^{22}$ The structures prepared are shown in Table 1.

For each of two series (Arg and Lys), equimolar mixtures were prepared and analysed by MALDI-TOF $\left(0.2 \mathrm{~mm}^{3}\right.$ of 2.5 $\mathrm{pmol} / \mathrm{mm}^{3}$ of each peptide conjugate was mixed with $0.2 \mathrm{~mm}^{3}$ of $10 \mathrm{mg} / \mathrm{cm}^{3}$ of $\alpha$-cyano-4-hydroxycinnamic acid and spotted onto a MALDI target for analysis). For the Arg series (Fig. 7), all derivatives had more intense peaks (17e, $1928 \mathrm{Da}$; 10i, $1971 \mathrm{Da}$; 40a, 1983 Da; 28i, $1998 \mathrm{Da}$ ) compared to the non-labelled 57 (1571 Da), with two derivatives (17e and 10i) substantially improving the detection.

Results of the MALDI-TOF comparison of the Lys series are shown on Fig. 8. The spectrum shows that two trityl derivatives, 10j (1942 Da) and 40b (1955 Da) is detected better than the control 58 (1542 Da).

A more detailed analysis of $\mathbf{1 7 e}$ (Glu-Fib labelled with the acid 14a) revealed an interesting deisotoping pattern (Fig. 9). While the non-labelled $\mathbf{5 7}$ upon deisotoping produces a typical single peak (data not shown), the 17e conjugate yields a "doublet", with $1 \mathrm{Da}$ mass difference. We believe that the doublet proves the presence of two different forms of 17e. As our experiments with model compound $10 \mathrm{~g}$ and tritanol clusters $17 \mathrm{c}, 17 \mathrm{~d}, 10 \mathrm{~h}$ and 56 suggest, tritanols can lose the hydroxyl and still not carry a charge, staying in a radical form instead. The charge for ionising the analyte

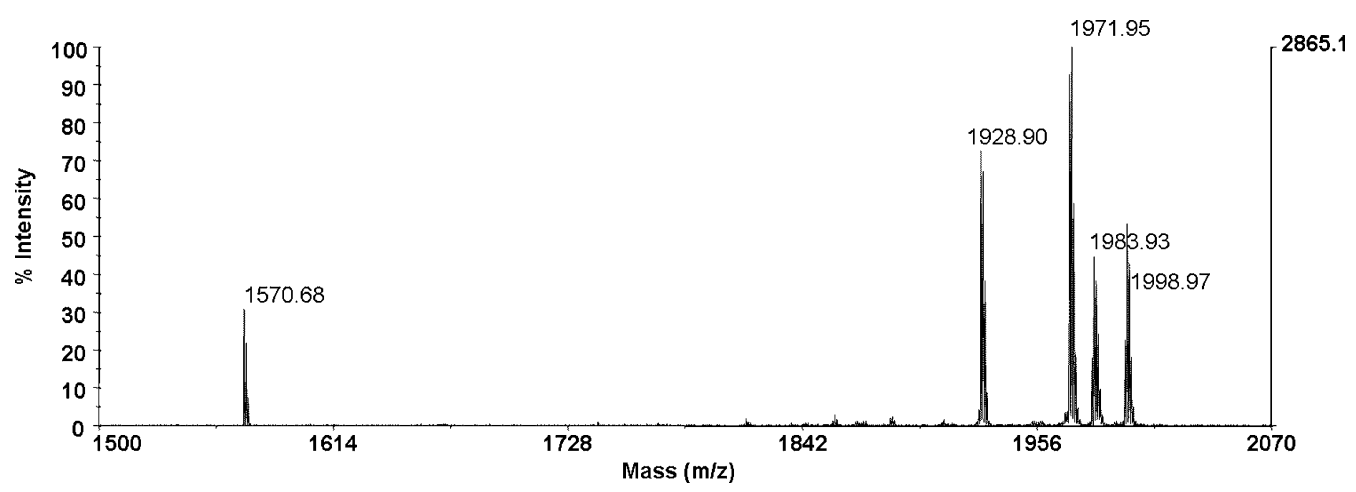

Fig. 7 Comparative MALDI-TOF analysis of an equimolar mixture of Glu-Fib 57 and its trityl-labelled derivatives 17e, 10i, 40a, and 28i.

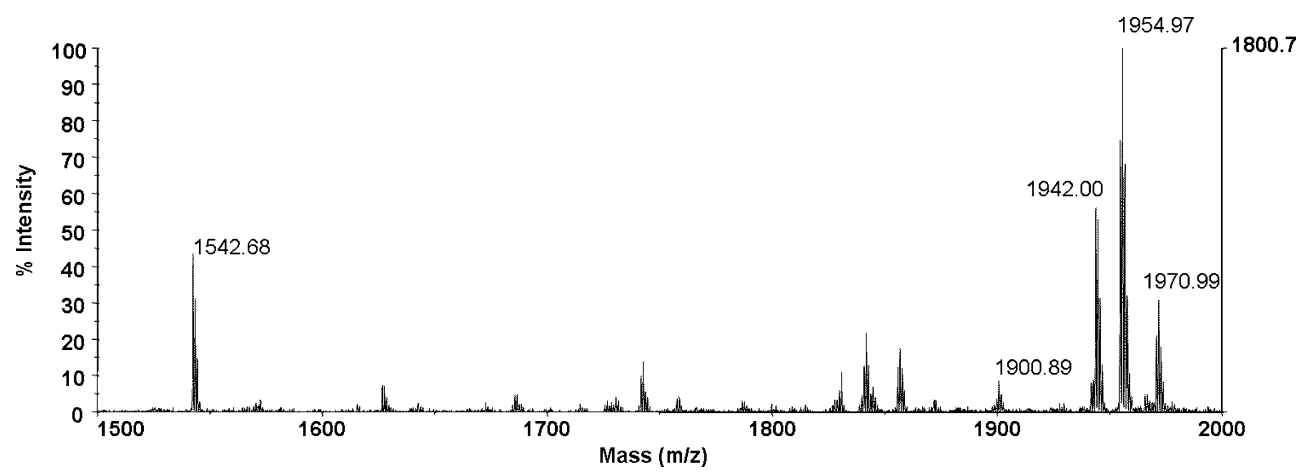

Fig. 8 Comparative MALDI-TOF analysis of an equimolar mixture of C-Lys-Glu-Fib $\mathbf{5 8}$ and its trityl-labelled derivatives $\mathbf{1 7 f}$, 10j, 40b, and $\mathbf{2 8 j}$. 


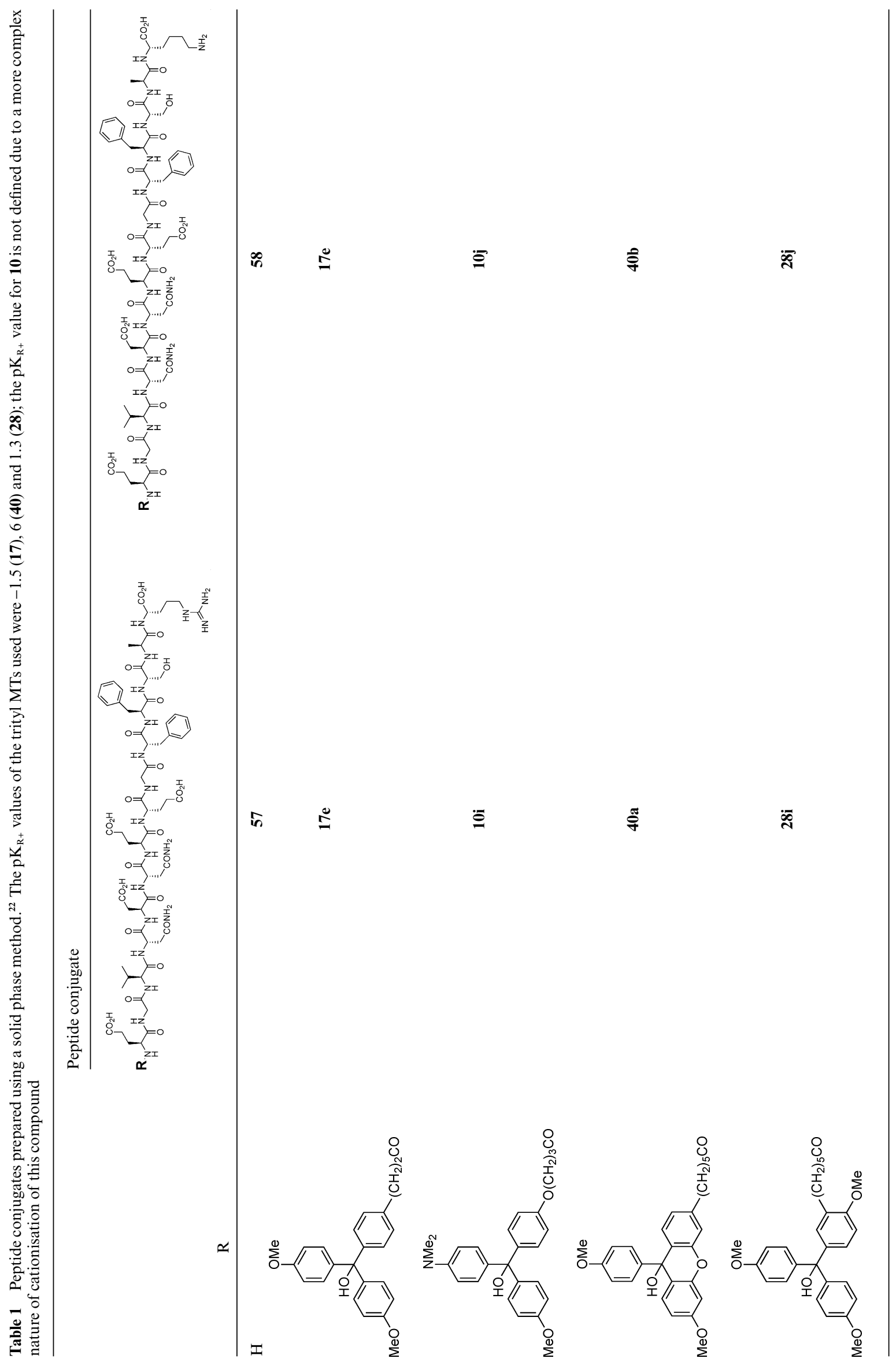



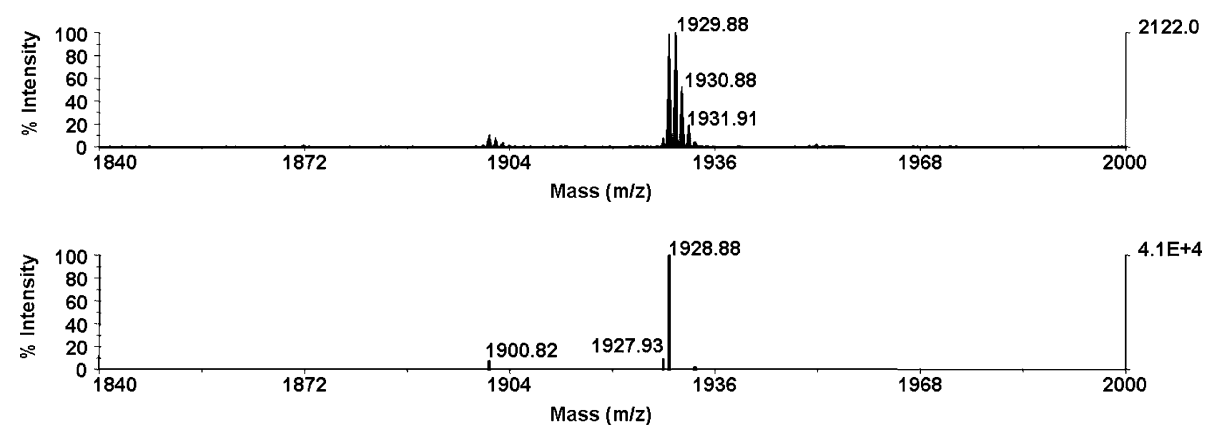

Fig. 9 MALDI-TOF analysis of $\mathbf{1 7 e}$ (top), and deisotoping of the same spectrum (bottom).

should thus come from elsewhere - and in this case it comes from a protonated guanidyl residue of Arg; 17e would therefore have a mass of $\left(\mathrm{MI}-\mathrm{OH}+\mathrm{H}^{+}\right)$Da. But this process could be in equilibrium with the trityl residue gaining the charge. Because double charging does not happen in these conditions (vide supra), this conjugate would therefore not be protonated and thus have a mass of $(\mathrm{MI}-\mathrm{OH}) \mathrm{Da}$. These two species, with a mass difference of $1 \mathrm{Da}$, are present simultaneously - as the two peaks with 1Da difference indicate. This is not the case for Lys terminated peptides, which have a lower basicity compared to Arg so that the charge would reside exclusively on the trityl.

Interestingly, the presence of this "doublet" in the Arg series was only observed for $\mathbf{1 7 e}$. The fact that $\mathbf{1 0}$, $\mathbf{4 0 a}$ and $\mathbf{2 8 \mathbf { i }}$ are not detected in the $[\mathrm{MI}-\mathrm{OH}+\mathrm{H}]^{+}$form but only in the $[\mathrm{MI}-\mathrm{OH}]^{+}$ form (deisotoping data not shown) suggests that due to the higher $\mathrm{pK}_{\mathrm{R}+}$ values of their trityl MTs compared to $17 \mathrm{e}$ all species would have the charge residing on the trityl. Thus, the attachment of trityl acid 14a to a peptide, although it did not always improve its detection, allows one to distinguish easily arginine-containing peptides. $^{23}$

Finally, we have tested the efficiency of peptide labelling with activated forms of our trityl MTs in homogenous conditions. Labelling of GluFib peptide in aqueous acetonitrile with activated ester 16a (See Experimental section) did not proceed to completion, as is obvious from Fig. 10. A solid-phase labelling method, which produces conjugates not contaminated with the starting peptides, will be reported elsewhere.

In some cases, double labelling was also detected (data not shown), involving both Lys and N-terminal amines. Non-complete conversion would require subsequent separation of non-labelled peptides from the reaction mix.
To test the labelling efficiency of maleimido-activated trityl MTs, we labelled a peptide, Laminin (CDPGYIGSR), with maleimido trityl 52 in acetonitrile (Fig. 11A). The efficiency of this reaction was comparable to that for 15a (cf. Fig. 10). A substantial improvement was achieved when pyridine was used instead of acetonitrile (Fig. 11B), indicating that pyridine might be a better solvent in bioconjugation reactions involving trityl MTs (see Experimental section). Once again, a solid-phase labelling would provide a necessary clean-up for the conjugation reactions (see Scheme 1; $\mathrm{GR}^{2}=$ solid phase); solid-phase trityl MT reagents will be reported elsewhere.

\section{Experimental}

\section{Instrumentation}

$500 \mathrm{MHz}{ }^{1} \mathrm{H}$ and $125.7 \mathrm{MHz}{ }^{13} \mathrm{C}$ NMR spectra were recorded on a Bruker DRX-500 spectrometer and referenced to DMSO$d_{6}(2.50 \mathrm{ppm}$ and $39.5 \mathrm{ppm}) .{ }^{24}{ }^{1} \mathrm{H}$ NMR coupling constants are reported in $\mathrm{Hz}$ and refer to apparent multiplicities. ${ }^{1} \mathrm{H}-{ }^{13} \mathrm{C}$ gradient-selected HMQC and HMBC spectra were obtained by using $2048\left(t_{2}\right) \times 256\left(t_{1}\right)$ complex point data sets, zero filled to $2048\left(F_{2}\right) \times 1024\left(F_{1}\right)$ points. The spectral widths were $13 \mathrm{ppm}$ and $200 \mathrm{ppm}$ for ${ }^{1} \mathrm{H}$ and ${ }^{13} \mathrm{C}$ dimensions, respectively. HMBC spectra were measured with $50 \mathrm{~ms}$ delay for evolution of long-range couplings. (MA)LDI-TOF mass spectra were obtained using a Voyager Elite Biospectrometry Research Station (PerSeptive Biosystems) in a positive ion mode. ESI-TOF HRMS spectra in positive ion mode were obtained using Micromass LCT reflection TOF mass spectrometer. Analytical thin-layer chromatography was performed on the Kieselgel $60 \mathrm{~F}_{254}$ precoated aluminium plates

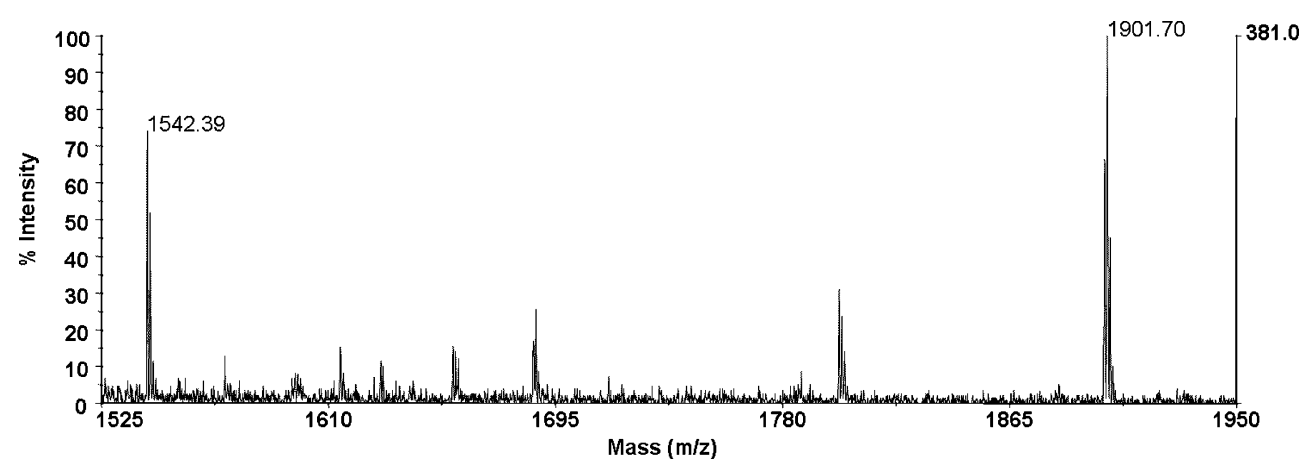

Fig. 10 Labelling of C-Lys-Glu-Fib 58 (1542 Da) with NHS-ester 15a. $1901 \mathrm{Da}$ is a monolabelled conjugate without the hydroxyl. 

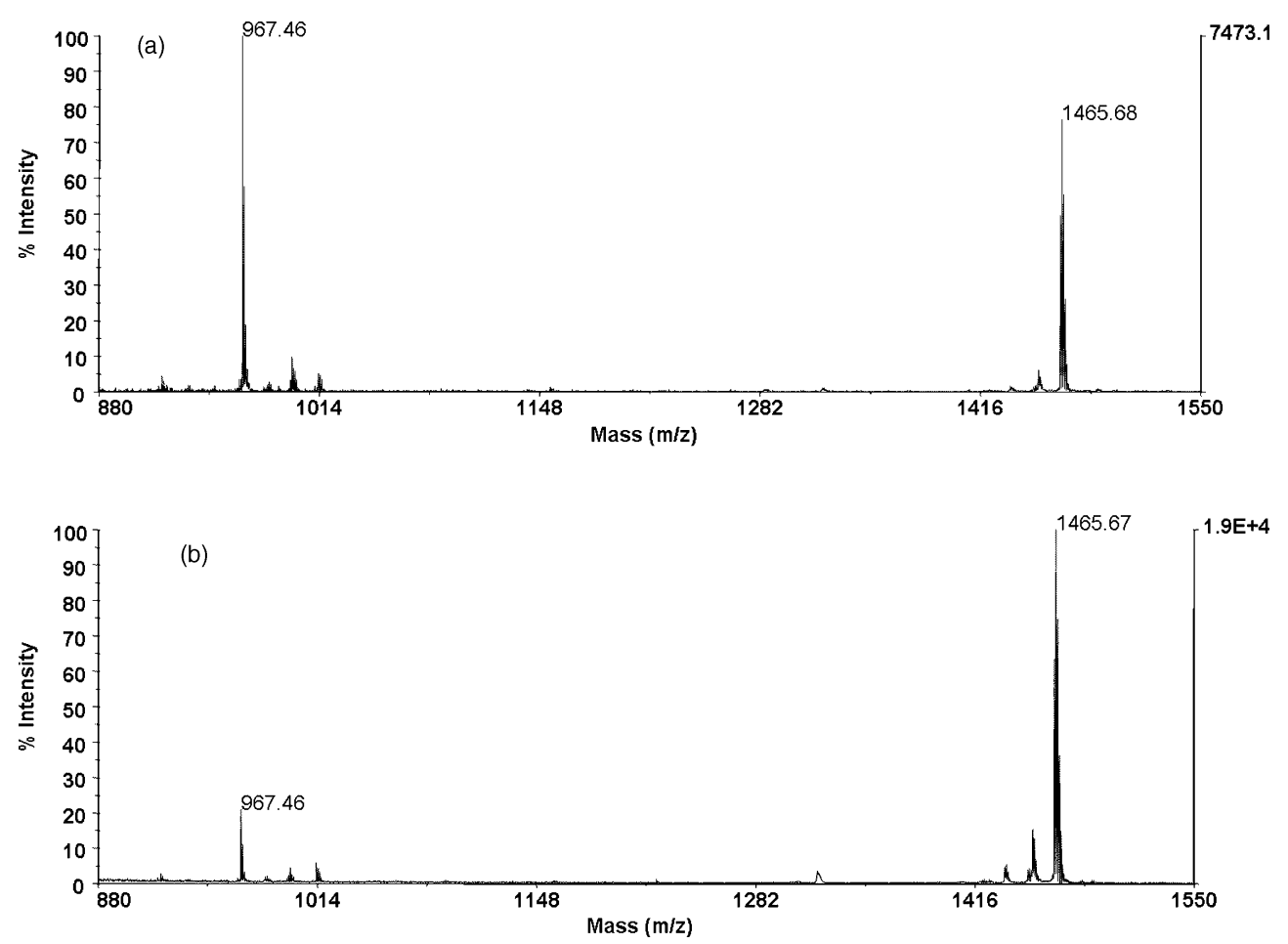

Fig. 11 Labelling of laminin (CDPGYIGSR) with maleimido-activated trityl $\mathbf{5 2}$ in acetonitrile (A) and in pyridine (B). Laminin, MW 967 Da; conjugate, MW $1465 \mathrm{Da}(\mathrm{MI}-\mathrm{OH})$.

(Merck), spots were visualised under UV light (254 nm). Column chromatography was performed on silica gel (Merck Kieselgel 60 $0.040-0.063 \mathrm{~mm})$.

\section{Reagents and solvents}

Reagents obtained from commercial suppliers were used as received. Solvents were mainly HPLC grade and used without further purification unless otherwise noted. DCM was always used freshly distilled over $\mathrm{CaH}_{2}$. THF was distilled over powdered $\mathrm{LiAlH}_{4}$ and stored over $4 \AA$ molecular sieves under nitrogen. DMF was freshly distilled under reduced pressure.

\section{Syntheses of activated trityl derivatives}

3-[5-(tert-Butyloxycarbonyl)pent-1-ynyl]-4,4'-dimethoxybenzophenone (22a). To a solution of 3-iodo-4,4'-dimethoxybenzophenone (4.50 g, $12.2 \mathrm{mmol})$ and tert-butyl 5-hexynoate $(2.10 \mathrm{~g}$, $12.5 \mathrm{mmol})$ in $\mathrm{DMF}\left(50 \mathrm{~cm}^{3}\right) \mathrm{Pd}\left(\mathrm{PPh}_{3}\right)_{4}(1.40 \mathrm{~g}, 1.22 \mathrm{mmol})$, $\mathrm{CuI}$ (465 mg, $2.44 \mathrm{mmol}), \mathrm{Et}_{3} \mathrm{~N}$ (2.55 $\left.\mathrm{cm}^{3}, 18.3 \mathrm{mmol}\right)$ were subsequently added. The mixture was stirred overnight under argon, then diluted with water $\left(200 \mathrm{~cm}^{3}\right)$ and extracted with EtOAc $\left(200 \mathrm{~cm}^{3}\right)$. The organic layer was washed with water $\left(4 \times 200 \mathrm{~cm}^{3}\right)$, $0.1 \mathrm{M}\left(\mathrm{NH}_{4}\right)_{2}$ EDTA $\left(4 \times 200 \mathrm{~cm}^{3}\right)$, dried over $\mathrm{Na}_{2} \mathrm{SO}_{4}$ and evaporated. The residue was purified by column chromatography in gradient of EtOAc in toluene (0 to 5\%). Yield $3.43 \mathrm{~g}(69 \%)$, viscous yellowish oil. $R_{\mathrm{f}} 0.36(10 \%$ EtOAc in $\mathrm{PhMe}(\mathrm{v} / \mathrm{v}))$. ESITOF HRMS: $m / z=409.2027[\mathrm{M}+\mathrm{H}]^{+}$, calc. for $\left[\mathrm{C}_{25} \mathrm{H}_{29} \mathrm{O}_{5}\right]^{+}$ 409.2010. ${ }^{1} \mathrm{H}$ NMR (DMSO- $\left.d_{6}\right): \delta_{\mathrm{H}}=7.72-7.67(\mathrm{~m}, 3 \mathrm{H}, \mathrm{H}-$ $\left.6,2^{\prime}, 6^{\prime}\right) ; 7.64\left(\mathrm{~d}, 1 \mathrm{H},{ }^{4} \mathrm{~J}=2.1 \mathrm{~Hz}, \mathrm{H}-2\right) ; 7.17(\mathrm{~d}, 1 \mathrm{H}, J=8.7 \mathrm{~Hz}$, $\mathrm{H}-5) ; 7.08$ (d, 2H, $\left.J=8.7 \mathrm{~Hz}, \mathrm{H}-3^{\prime}, 5^{\prime}\right) ; 3.91$ (s, 3H, OCH O $_{3}$; 3.86 $\left(\mathrm{s}, 3 \mathrm{H}, \mathrm{OCH}_{3}\right) ; 2.47\left(\mathrm{t}, 2 \mathrm{H}, J=7.0 \mathrm{~Hz}, \equiv \mathrm{CCH}_{2}\right) ; 2.37(\mathrm{t}, 2 \mathrm{H}, J=$
7.4 Hz, $\left.\mathrm{COCH}_{2}\right) ; 1.75\left(\mathrm{~m}, 2 \mathrm{H}, \mathrm{CH}_{2} \mathrm{CH}_{2} \mathrm{CH}_{2}\right) ; 1.39$ (s, 9H, $\left.\mathrm{CCH}_{3}\right)$. ${ }^{13} \mathrm{C}$ NMR (DMSO- $\left.d_{6}\right): \delta_{\mathrm{C}}=192.64$ (ArCOAr), $171.86(\mathrm{OCO})$, $162.74\left(\mathrm{C}^{\prime}\right), 162.60$ (C4), 134.36 (C2), 131.86 (2C, C2',6'), 131.48 (C6), 129.93 (C1), $129.74\left(\mathrm{Cl}^{\prime}\right), 113.87$ (2C, C3',5'), 112.23 (C3), $110.98(\mathrm{C} 5), 94.42(\mathrm{ArC} \equiv C), 79.65\left(C\left(\mathrm{CH}_{3}\right)_{3}\right), 76.65(\mathrm{ArC} \equiv), 56.12$ $\left(4-\mathrm{OCH}_{3}\right), 55.56\left(4^{\prime}-\mathrm{OCH}_{3}\right), 33.67\left(\mathrm{COCH}_{2}\right), 27.79\left(3 \mathrm{C}, \mathrm{C}\left(\mathrm{CH}_{3}\right)_{3}\right)$, $23.77\left(\mathrm{CH}_{2} \mathrm{CH}_{2} \mathrm{CH}_{2}\right), 18.30\left(\equiv \mathrm{CCH}_{2}\right)$.

3 - [5-(tert - Butyloxycarbonyl ) pentyl $]-4,4$ '-dimethoxybenzophenone (23a). To a solution of 3-[5-(tert-butyloxycarbonyl)pent-1ynyl]-4,4'-dimethoxybenzophenone (2.027 g, $4.96 \mathrm{mmol})$ in EOAc $\left(40 \mathrm{~cm}^{3}\right) 10 \% \mathrm{Pd} / \mathrm{C}(100 \mathrm{mg})$ was added and the mixture was hydrogenated at 150 Torr for $24 \mathrm{~h}$, filtered, diluted with EtOAc $\left(150 \mathrm{~cm}^{3}\right)$, washed with $5 \% \mathrm{NaHCO}_{3}\left(100 \mathrm{~cm}^{3}\right)$ and $0.1 \mathrm{M}$ $\left(\mathrm{NH}_{4}\right)_{2}$ EDTA $\left(100 \mathrm{~cm}^{3}\right)$, dried over $\mathrm{Na}_{2} \mathrm{SO}_{4}$, evaporated, and the residue was purified by column chromatography $(0 \rightarrow 10 \%$ EtOAc in toluene). Yield $1.493 \mathrm{~g}(73 \%)$, colourless oil. $R_{\mathrm{f}} 0.45(10 \%$ EtOAc in PhMe (v/v)). ESI-TOF HRMS: $m / z=413.2304[\mathrm{M}+\mathrm{H}]^{+}$, calc. for $\left[\mathrm{C}_{25} \mathrm{H}_{33} \mathrm{O}_{5}\right]^{+}$413.2323. ${ }^{1} \mathrm{H}$ NMR (DMSO- $\left.d_{6}\right): \delta_{\mathrm{H}}=7.69$ $\left(\mathrm{d}, 2 \mathrm{H}, J=8.7 \mathrm{~Hz}, \mathrm{H}-2^{\prime}, 6^{\prime}\right) ; 7.58\left(\mathrm{dd}, 1 \mathrm{H}, J=8.4 \mathrm{~Hz},{ }^{4} J=\right.$ $2.2 \mathrm{~Hz}, \mathrm{H}-6) ; 7.53$ (d, $\left.1 \mathrm{H},{ }^{4} \mathrm{~J}=2.2 \mathrm{~Hz}, \mathrm{H}-2\right) ; 7.07$ (m, 3H, H$\left.5,3^{\prime}, 5^{\prime}\right) ; 3.88\left(\mathrm{~s}, 3 \mathrm{H}, \mathrm{OCH}_{3}\right) ; 3.86\left(\mathrm{~s}, 3 \mathrm{H}, \mathrm{OCH}_{3}\right) ; 2.59(\mathrm{t}, 2 \mathrm{H}$, $\left.J=7.4 \mathrm{~Hz}, \mathrm{ArCH}_{2}\right) ; 2.16\left(\mathrm{t}, 2 \mathrm{H}, J=7.3 \mathrm{~Hz}, \mathrm{COCH}_{2}\right) ; 1.57-$ $1.47\left(\mathrm{~m}, 4 \mathrm{H}, \mathrm{COCH}_{2} \mathrm{CH}_{2} \mathrm{CH}_{2} \mathrm{CH}_{2}\right) ; 1.36\left(\mathrm{~s}, 9 \mathrm{H}, \mathrm{CCH}_{3}\right) ; 1.28$ $\left(\mathrm{m}, 2 \mathrm{H}, \mathrm{COCH}_{2} \mathrm{CH}_{2} \mathrm{CH}_{2}\right.$ ). ${ }^{13} \mathrm{C}$ NMR (DMSO- $\left.d_{6}\right): \delta_{\mathrm{C}}=193.38$ (ArCOAr), 172.28 (OCO), 162.51 (C4'), 160.51 (C4), 131.81 (2C, C2', 6'), 131.08 (C2), 130.23 (C3), 130.09 (C6), 129.93 (C1), 129.67 $\left.\left(\mathrm{Cl}^{\prime}\right), 113.77\left(2 \mathrm{C}, \mathrm{C}^{\prime}, 5^{\prime}\right), 110.17(\mathrm{C} 5), 79.33\left(\mathrm{C}^{\prime} \mathrm{CH}_{3}\right)_{3}\right), 55.65(4-$ $\left.\mathrm{OCH}_{3}\right), 55.33\left(4^{\prime}-\mathrm{OCH}_{3}\right), 34.73\left(\mathrm{COCH}_{2}\right), 29.31\left(\mathrm{ArCH}_{2}\right), 28.75$ $\left(\mathrm{ArCH}_{2} \mathrm{CH}_{2}\right), 28.17\left(\mathrm{ArCH}_{2} \mathrm{CH}_{2} \mathrm{CH}_{2}\right), 27.79\left(3 \mathrm{C}, \mathrm{C}\left(\mathrm{CH}_{3}\right)_{3}\right), 24.48$ $\left(\mathrm{COCH}_{2} \mathrm{CH}_{2}\right)$. 
3-[5-(tert-Butyloxycarbonyl)pentyl]-4,4', $4^{\prime \prime}$-trimethoxytritanol (24a). To a stirred solution 3-[5-(tert-butyloxycarbonyl)pentyl]4,4'-dimethoxybenzophenone (412 $\mathrm{mg} ; 1.0 \mathrm{mmol})$ in dry THF $\left(10 \mathrm{~cm}^{3}\right) 1 \mathrm{M}$ 4-methoxyphenylmagnesium bromide $\left(1.2 \mathrm{~cm}^{3}\right.$, $1.2 \mathrm{mmol}$ ) was added in one portion under argon, and the mixture was kept at ambient temperature overnight (monitoring by TLC in EtOAc-toluene 1:3). The reaction was diluted with water $\left(50 \mathrm{~cm}^{3}\right)$ and saturated aq. $\mathrm{NH}_{4} \mathrm{Cl}\left(20 \mathrm{~cm}^{3}\right)$, and then extracted with EtOAc $\left(2 \times 100 \mathrm{~cm}^{3}\right)$. The organic phase was dried over $\mathrm{Na}_{2} \mathrm{SO}_{4}$, evaporated, and chromatographed on aluminium oxide in $0 \rightarrow 10 \%$ EtOAc in toluene with $0.5 \%$ of $\mathrm{Et}_{3} \mathrm{~N}$ to give the desired compound as a colourless oil. Yield $274 \mathrm{mg}(53 \%) . R_{\mathrm{f}} 0.43(10 \%$ EtOAc in PhMe (v/v)). ESI-TOF HRMS: $m / z=503.2811$ [M$\mathrm{OH}]^{+}$, calc. for $\left[\mathrm{C}_{32} \mathrm{H}_{39} \mathrm{O}_{5}\right]^{+}$503.2792. ${ }^{1} \mathrm{H}$ NMR (DMSO- $\left.d_{6}\right): \delta_{\mathrm{H}}=$ 7.06 (m, 4H, H-2', 6', 2", $\left.6^{\prime \prime}\right) ; 6.97$ (d, $\left.1 \mathrm{H},{ }^{4} \mathrm{~J}=1.9 \mathrm{~Hz}, \mathrm{H}-2\right) ; 6.88-$ $6.79\left(\mathrm{~m}, 6 \mathrm{H}, \mathrm{H}-5,6,3^{\prime}, 5^{\prime}, 3^{\prime \prime}, 5^{\prime \prime}\right) ; 6.02(\mathrm{~s}, 1 \mathrm{H}, \mathrm{OH}) ; 3.74(\mathrm{~s}, 3 \mathrm{H}$, $\left.\mathrm{OCH}_{3}\right) ; 3.72\left(\mathrm{~s}, 6 \mathrm{H}, \mathrm{OCH}_{3}\right) ; 2.45\left(\mathrm{t}, 2 \mathrm{H}, J=7.5 \mathrm{~Hz}, \mathrm{ArCH}_{2}\right) ; 2.12$ (t, $\left.2 \mathrm{H}, J=7.3 \mathrm{~Hz}, \mathrm{COCH}_{2}\right) ; 1.44\left(\mathrm{~m}, 4 \mathrm{H}, \mathrm{COCH}_{2} \mathrm{CH}_{2} \mathrm{CH}_{2} \mathrm{CH}_{2}\right.$ ); $1.37\left(\mathrm{~s}, 9 \mathrm{H}, \mathrm{CCH}_{3}\right) ; 1.20\left(\mathrm{~m}, 2 \mathrm{H}, \mathrm{COCH}_{2} \mathrm{CH}_{2} \mathrm{CH}_{2}\right) .{ }^{13} \mathrm{C} \mathrm{NMR}$ $\left(\mathrm{DMSO}-d_{6}\right): \delta_{\mathrm{C}}=172.27(\mathrm{CO}), 157.76\left(2 \mathrm{C}, \mathrm{C}^{\prime}, 4^{\prime \prime}\right), 155.61$ (C4), 140.68 (2C, $\left.\mathrm{C1}^{\prime}, 1^{\prime \prime}\right), 140.08$ (C1), 129.25 (C3), 128.89 (4C, $\left.\mathrm{C}^{\prime}, 6^{\prime}, 2^{\prime \prime}, 6^{\prime \prime}\right), 128.64$ (C2), 126.36 (C6), 112.68 (4C, C3', $\left.5^{\prime}, 3^{\prime \prime}, 5^{\prime \prime}\right)$, 109.35 (C5), $79.67\left(\mathrm{Ar}_{3} \mathrm{COH}\right), 79.34\left(\mathrm{C}\left(\mathrm{CH}_{3}\right)_{3}\right), 55.31\left(4-\mathrm{OCH}_{3}\right)$, $55.02\left(2 \mathrm{C}, 4^{\prime}-\mathrm{OCH}_{3}, 4^{\prime \prime}-\mathrm{OCH}_{3}\right), 34.74\left(\mathrm{COCH}_{2}\right), 29.62\left(\mathrm{ArCH}_{2}\right)$, $28.99\left(\mathrm{ArCH}_{2} \mathrm{CH}_{2}\right), 28.14\left(\mathrm{ArCH}_{2} \mathrm{CH}_{2} \mathrm{CH}_{2}\right), 27.79\left(3 \mathrm{C}, \mathrm{C}\left(\mathrm{CH}_{3}\right)_{3}\right)$, $24.45\left(\mathrm{COCH}_{2} \mathrm{CH}_{2}\right)$.

3-[5-(Succinimid-1-yloxycarbonyl)pentyl]-4,4',4'-trimethoxytritanol (26a). To a stirred solution of 3-[5-(tert-butyloxy-

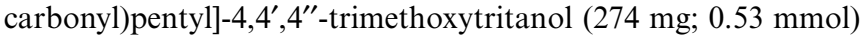
in dry DCM $\left(2 \mathrm{~cm}^{3}\right)$ trifluoroacetic acid $\left(2 \mathrm{~cm}^{3}\right)$ was added in one portion and the mixture was stirred at ambient temperature for $3 \mathrm{~h}$, then evaporated, and co-evaporated with DCM $(4 \times$ $50 \mathrm{~cm}^{3}$ ) to give free acid. An analytical sample of the acid 25a was purified by column chromatography on silica gel $(20 \rightarrow 30 \%$ acetone in toluene). $R_{\mathrm{f}} 0.30\left(30 \% \mathrm{Me}_{2} \mathrm{CO}\right.$ in $\left.\mathrm{PhMe}(\mathrm{v} / \mathrm{v})\right) .{ }^{1} \mathrm{H}$ NMR (DMSO- $d_{6}$ ): $\delta_{\mathrm{H}}=11.92$ (br.s, $1 \mathrm{H}, \mathrm{CO}_{2} H$ ); 7.07 (d, 4H, $\left.J=8.7 \mathrm{~Hz}, \mathrm{H}-2^{\prime}, 6^{\prime}, 2^{\prime \prime}, 6^{\prime \prime}\right) ; 6.98\left(\mathrm{~d}, 1 \mathrm{H},{ }^{4} J=1.9 \mathrm{~Hz}, \mathrm{H}-2\right)$; $6.88\left(\mathrm{dd}, 1 \mathrm{H}, J=8.4 \mathrm{~Hz},{ }^{4} J=1.9 \mathrm{~Hz}, \mathrm{H}-6\right)$; $6.85-6.79(\mathrm{~m}$, $\left.5 \mathrm{H}, \mathrm{H}-5,3^{\prime}, 5^{\prime}, 3^{\prime \prime}, 5^{\prime \prime}\right) ; 6.02$ (br.s, $1 \mathrm{H}, \mathrm{OH}$ ); 3.75 (s, 3H, $\mathrm{OCH}_{3}$ ); $3.72\left(\mathrm{~s}, 6 \mathrm{H}, \mathrm{OCH}_{3}\right) ; 2.45\left(\mathrm{t}, 2 \mathrm{H}, J=7.8 \mathrm{~Hz}, \mathrm{ArCH}_{2}\right) ; 2.15(\mathrm{t}$, $\left.2 \mathrm{H}, J=7.3 \mathrm{~Hz}, \mathrm{COCH}_{2}\right) ; 1.45\left(\mathrm{~m}, 4 \mathrm{H}, \mathrm{COCH}_{2} \mathrm{CH}_{2} \mathrm{CH}_{2} \mathrm{CH}_{2}\right)$; $1.22\left(\mathrm{~m}, 2 \mathrm{H}, \mathrm{COCH}_{2} \mathrm{CH}_{2} \mathrm{CH}_{2}\right) \cdot{ }^{13} \mathrm{C} \mathrm{NMR}\left(\mathrm{DMSO}-d_{6}\right): \delta_{\mathrm{C}}=$ $174.47\left(\mathrm{CO}_{2} \mathrm{H}\right), 157.76\left(2 \mathrm{C}, \mathrm{C}^{\prime}, 4^{\prime \prime}\right), 155.63(\mathrm{C} 4), 140.68(2 \mathrm{C}$, $\left.\mathrm{C1}^{\prime}, 1^{\prime \prime}\right), 140.10$ (C1), 129.29 (C3), 128.89 (4C, C2',6 $\left.6^{\prime \prime}, 6^{\prime \prime}\right)$, 128.68 (C2), 126.37 (C6), 112.70 (4C, C3',5',3",5"), 109.38 (C5), $79.68\left(\mathrm{Ar}_{3} \mathrm{COH}\right), 55.32\left(4-\mathrm{OCH}_{3}\right), 55.03\left(2 \mathrm{C}, 4^{\prime}-\mathrm{OCH}_{3}\right.$, 4"- $\left.\mathrm{OCH}_{3}\right), 33.69\left(\mathrm{CH}_{2} \mathrm{CO}_{2} \mathrm{H}\right), 29.66\left(\mathrm{ArCH}_{2}\right), 29.11,28.36$, $24.37\left(\mathrm{ArCH}_{2} \mathrm{CH}_{2} \mathrm{CH}_{2} \mathrm{CH}_{2}\right)$. The product was dissolved in $\operatorname{DCM}\left(15 \mathrm{~cm}^{3}\right)$, and triethylamine $\left(0.60 \mathrm{~cm}^{3}, 4.3 \mathrm{mmol}\right)$ and $N, N$-disuccinimidyl carbonate $(556 \mathrm{mg}, 2.17 \mathrm{mmol})$ were added and the mixture was stirred overnight, then evaporated, dissolved in EtOAc $\left(50 \mathrm{~cm}^{3}\right)$, washed with $5 \% \mathrm{NaHCO}_{3}\left(50 \mathrm{~cm}^{3}\right)$ and water $\left(50 \mathrm{~cm}^{3}\right)$, dried over $\mathrm{Na}_{2} \mathrm{SO}_{4}$, evaporated, and the residue was purified by column chromatography $(15 \rightarrow 30 \%$ EtOAc in toluene). Yield $277 \mathrm{mg}(93 \%)$, pink amorphous solid. $R_{\mathrm{f}}$ $0.64\left(30 \% \mathrm{Me}_{2} \mathrm{CO}\right.$ in PhMe (v/v)). ESI-TOF HRMS: $m / z=$ $544.2388[\mathrm{M}-\mathrm{OH}]^{+}$, calc. for $\left[\mathrm{C}_{32} \mathrm{H}_{34} \mathrm{NO}_{7}\right]^{+}$544.2330. ${ }^{1} \mathrm{H} \mathrm{NMR}$ $\left(\mathrm{DMSO}-d_{6}\right): \delta_{\mathrm{H}}=7.71(\mathrm{~d}, 1 \mathrm{H}, J=8.9 \mathrm{~Hz}, \mathrm{H}-5) ; 7.07$ (d, $4 \mathrm{H}, J=$ $\left.8.9 \mathrm{~Hz}, \mathrm{H}-2^{\prime}, 6^{\prime}, 2^{\prime \prime}, 6^{\prime \prime}\right) ; 6.99$ (d, $\left.1 \mathrm{H},{ }^{4} \mathrm{~J}=2.1 \mathrm{~Hz}, \mathrm{H}-2\right) ; 6.89-6.78$ $\left(\mathrm{m}, 5 \mathrm{H}, \mathrm{H}-6,3^{\prime}, 5^{\prime}, 3^{\prime \prime}, 5^{\prime \prime}\right) ; 6.02(\mathrm{~s}, 1 \mathrm{H}, \mathrm{OH}) ; 3.89$ (s, 3H), 3.86 (s, 6H) $\left(\mathrm{OCH}_{3}\right) ; 2.80\left(\mathrm{~s}, 4 \mathrm{H}, \mathrm{COCH}_{2} \mathrm{CH}_{2} \mathrm{CO}\right) ; 2.61(\mathrm{t}, 2 \mathrm{H}, J=$ $7.3 \mathrm{~Hz}), 2.46(\mathrm{t}, 2 \mathrm{H}, J=7.6 \mathrm{~Hz})\left(\mathrm{ArCH}_{2} \mathrm{CH}_{2} \mathrm{CH}_{2} \mathrm{CH}_{2} \mathrm{CH}_{2}\right) ; 1.54$ $(\mathrm{m}, 2 \mathrm{H}), 1.44(\mathrm{~m}, 2 \mathrm{H}), 1.32(\mathrm{~m}, 2 \mathrm{H})\left(\mathrm{ArCH}_{2} \mathrm{CH}_{2} \mathrm{CH}_{2}\right) .{ }^{13} \mathrm{C} \mathrm{NMR}$ $\left(\mathrm{DMSO}-d_{6}\right): \delta_{\mathrm{C}}=171.22\left(\mathrm{CO}_{2} \mathrm{~N}\right), 170.37\left(2 \mathrm{C}, \mathrm{COCH}_{2} \mathrm{CH}_{2} \mathrm{CO}\right)$, $157.75\left(2 \mathrm{C}, \mathrm{C}^{\prime}, 4^{\prime \prime}\right), 155.66(\mathrm{C} 4), 140.64$ (2C, $\left.\mathrm{Cl}^{\prime}, 1^{\prime \prime}\right), 140.12(\mathrm{C} 1)$, 129.28 (C3), 128.87 (4C, C2',6',2",6"), 128.66 (C2), 126.35 (C6), 112.68 (4C, C3', $\left.5^{\prime}, 3^{\prime \prime}, 5^{\prime \prime}\right), 109.36$ (C5), $79.65\left(\mathrm{Ar}_{3} \mathrm{COH}\right), 55.30$ $\left(4-\mathrm{OCH}_{3}\right), 55.01\left(2 \mathrm{C}, 4^{\prime}-\mathrm{OCH}_{3}, 4^{\prime \prime}-\mathrm{OCH}_{3}\right), 33.67\left(\mathrm{CH}_{2} \mathrm{CO}_{2} \mathrm{H}\right)$, $29.64\left(\mathrm{ArCH}_{2}\right), 29.10,28.35,24.39\left(\mathrm{ArCH}_{2} \mathrm{CH}_{2} \mathrm{CH}_{2} \mathrm{CH}_{2}\right), 22.48$ (2C, $\mathrm{COCH}_{2} \mathrm{CH}_{2} \mathrm{CO}$ ).

3-(5-Hydroxypent-1-ynyl)-4,4'-dimethoxybenzophenone (46). was prepared similar to 22a from 3-iodo-4,4'-dimethoxybenzophenone (3.16 g, $8.58 \mathrm{mmol})$, 4-pentynol-1 (1.20 $\left.\mathrm{cm}^{3}, 12.9 \mathrm{mmol}\right)$ $\mathrm{PdCl}_{2}$ (152 mg, $0.86 \mathrm{mmol}$ ), $\mathrm{PPh}_{3}$ (450 mg, $\left.1.72 \mathrm{mmol}\right), \mathrm{CuI}$ (82 mg, $0.43 \mathrm{mmol}), \mathrm{Et}_{3} \mathrm{~N}\left(2.4 \mathrm{~cm}^{3}, 17.2 \mathrm{mmol}\right)$ in DMF $\left(30 \mathrm{~cm}^{3}\right)$ and purified by chromatography on silica gel in gradient of EtOAc in toluene ( 0 to $50 \%$ ). Yield $2.55 \mathrm{~g}(91 \%)$, viscous yellowish oil. $R_{\mathrm{f}}$ 0.47 (EtOAc). ESI-TOF HRMS: $m / z=325.1427[\mathrm{M}+\mathrm{H}]^{+}$, calc. for $\left[\mathrm{C}_{20} \mathrm{H}_{21} \mathrm{O}_{4}\right]^{+} 325.1434 .{ }^{1} \mathrm{H}$ NMR (DMSO- $d_{6}$ ): $\delta_{\mathrm{H}}=7.72-7.66$ (m, 3H, H-6,2', 6'); 7.63 (d, 1H, $\left.{ }^{4} J=2.1 \mathrm{~Hz}, \mathrm{H}-2\right) ; 7.17$ (d, 1H, $J=8.9 \mathrm{~Hz}, \mathrm{H}-5) ; 7.09$ (d, $\left.2 \mathrm{H}, J=8.6 \mathrm{~Hz}, \mathrm{H}-3^{\prime}, 5^{\prime}\right) ; 4.50(\mathrm{t}, 1 \mathrm{H}$, $J=5.1 \mathrm{~Hz}, \mathrm{OH}) ; 3.91(\mathrm{~s}, 3 \mathrm{H}), 3.86(\mathrm{~s}, 3 \mathrm{H})\left(\mathrm{OCH}_{3}\right) ; 3.52(\mathrm{~m}$, $\left.2 \mathrm{H}, \mathrm{CH}_{2} \mathrm{OH}\right) ; 2.48\left(\mathrm{t}, 2 \mathrm{H}, J=7.0 \mathrm{~Hz}, \equiv \mathrm{CCH}_{2}\right) ; 1.68(\mathrm{~m}, 2 \mathrm{H}$, $\mathrm{CH}_{2} \mathrm{CH}_{2} \mathrm{CH}_{2}$ ). ${ }^{13} \mathrm{C}$ NMR (DMSO- $d_{6}$ ): $\delta_{\mathrm{C}}=192.67$ (ArCOAr), $162.72\left(\mathrm{C}^{\prime}\right), 162.58(\mathrm{C} 4), 134.34(\mathrm{C} 2), 131.85$ (2C, C2', 6') 131.45 (C6), 129.91 (C1), $129.74\left(\mathrm{Cl}^{\prime}\right), 113.86$ (2C, C3',5'), 112.21 (C3), 110.97 (C5), 94.38 ( $\mathrm{ArC} \equiv C), 76.63(\mathrm{ArC} \equiv), 60.35\left(\mathrm{CH}_{2} \mathrm{OH}\right)$, $56.10\left(4-\mathrm{OCH}_{3}\right), 55.56\left(4^{\prime}-\mathrm{OCH}_{3}\right), 30.18\left(\mathrm{CH}_{2} \mathrm{CH}_{2} \mathrm{CH}_{2}\right), 14.95$ $\left(\equiv \mathrm{CCH}_{2}\right)$.

3-(5-Hydroxypentyl)-4,4'-dimethoxybenzophenone (47). A solution of 3-(5-hydroxypent-1-ynyl)-4,4'-dimethoxybenzophenone $(4.15 \mathrm{~g}, 12.8 \mathrm{mmol})$ in EtOAc $\left(50 \mathrm{~cm}^{3}\right)$ was hydrogenated as above in the presence of $10 \% \mathrm{Pd} / \mathrm{C}(300 \mathrm{mg})$. The product was isolated by chromatography on silica gel (0 to $50 \%$ gradient of EtOAc in toluene); white solid (3.32 g, 79\%). $R_{\mathrm{f}} 0.76$ (EtOAc), mp 101-102 (EtOH). ESI-TOF HRMS: $m / z=329.1698[\mathrm{M}+\mathrm{H}]^{+}$, calc. for $\left[\mathrm{C}_{20} \mathrm{H}_{25} \mathrm{O}_{4}\right]^{+} 329.1747 .{ }^{1} \mathrm{H}$ NMR (DMSO- $\left.d_{6}\right): \delta_{\mathrm{H}}=7.70(\mathrm{~d}, 2 \mathrm{H}, J=$ $\left.8.8 \mathrm{~Hz}, \mathrm{H}-2^{\prime}, 6^{\prime}\right) ; 7.58\left(\mathrm{dd}, 1 \mathrm{H}, J=8.7 \mathrm{~Hz},{ }^{4} J=2.1 \mathrm{~Hz}, \mathrm{H}-6\right) ; 7.53$ $\left(\mathrm{d}, 1 \mathrm{H},{ }^{4} \mathrm{~J}=2.1 \mathrm{~Hz}, \mathrm{H}-2\right) ; 7.10-7.05\left(\mathrm{~m}, 3 \mathrm{H}, \mathrm{H}-5,3^{\prime}, 5^{\prime}\right) ; 4.31(\mathrm{t}, 1 \mathrm{H}$, $J=5.0 \mathrm{~Hz}, \mathrm{OH}) ; 3.88(\mathrm{~s}, 3 \mathrm{H}), 3.86(\mathrm{~s}, 3 \mathrm{H})\left(\mathrm{OCH}_{3}\right) ; 3.38(\mathrm{~m}, 2 \mathrm{H}$, $\left.\mathrm{CH}_{2} \mathrm{OH}\right) ; 2.60$ (t, 2H, J=7.6 Hz, $\left.\mathrm{ArCH}_{2}\right) ; 1.54(\mathrm{~m}, 2 \mathrm{H}), 1.44(\mathrm{~m}$, $\left.2 \mathrm{H}), 1.32(\mathrm{~m}, 2 \mathrm{H}), \mathrm{CH}_{2} \mathrm{CH}_{2} \mathrm{CH}_{2} \mathrm{CH}_{2} \mathrm{CH}_{2}\right) .{ }^{13} \mathrm{C}$ NMR (DMSO$\left.d_{6}\right): \delta_{\mathrm{C}}=193.43(\mathrm{ArCOAr}), 162.52\left(\mathrm{C}^{\prime}\right), 160.53(\mathrm{C} 4), 131.84(2 \mathrm{C}$, $\left.\mathrm{C}^{\prime}, 6^{\prime}\right), 131.08$ (C2), 130.26 (C3), 130.24 (C6), 129.93 (C1), 129.66 $\left(\mathrm{Cl}^{\prime}\right), 113.76\left(2 \mathrm{C}, \mathrm{C3}^{\prime}, 5^{\prime}\right), 110.17$ (C5), $60.73\left(\mathrm{CH}_{2} \mathrm{OH}\right), 55.77$ (4$\left.\mathrm{OCH}_{3}\right), 55.54\left(4^{\prime}-\mathrm{OCH}_{3}\right), 32.41\left(\mathrm{CH}_{2} \mathrm{CH}_{2} \mathrm{OH}\right), 29.54\left(\mathrm{ArCH}_{2}\right)$, $29.09\left(\mathrm{ArCH}_{2} \mathrm{CH}_{2}\right), 25.44\left(\mathrm{ArCH}_{2} \mathrm{CH}_{2} \mathrm{CH}_{2}\right)$.

3-[5-(Tetrahydropyran-2-yloxy)pentyl]-4,4'-dimethoxybenzophenone (48). To a solution of 3-(5-hydroxypentyl)-4,4'-dimethoxybenzophenone (542 $\mathrm{mg}, 1.65 \mathrm{mmol})$ in DCM $\left(10 \mathrm{~cm}^{3}\right)$ DHP $\left(0.17 \mathrm{~cm}^{3}, 1.82 \mathrm{mmol}\right)$ and $\mathrm{TsOH} \cdot \mathrm{H}_{2} \mathrm{O}(16 \mathrm{mg}, 0.08 \mathrm{mmol})$ were added and the mixture was stirred for $1.5 \mathrm{~h}$ at ambient temperature (TLC control in $10 \%$ EtOAc in toluene). Solid $\mathrm{NaHCO}_{3}(0.5 \mathrm{~g})$ was added and after $5 \mathrm{~min}$ the mixture was filtered, evaporated, and the residue was chromatographed on silica gel $3 \%$ EtOAc 
and $1 \% \mathrm{Et}_{3} \mathrm{~N}$ in toluene) to give the desired compound as a colourless oil (441 mg, 65\%). $R_{\mathrm{f}} 0.33(10 \%$ EtOAc in PhMe (v/v) + $\left.1 \% \mathrm{Et}_{3} \mathrm{~N}\right)$. ESI-TOF HRMS: $m / z=413.2341[\mathrm{M}+\mathrm{H}]^{+}$, calc. for $\left[\mathrm{C}_{25} \mathrm{H}_{33} \mathrm{O}_{5}\right]^{+}$413.2323. ${ }^{1} \mathrm{H}$ NMR (DMSO- $\left.d_{6}\right): \delta_{\mathrm{H}}=7.78(\mathrm{~d}, 2 \mathrm{H}$, $\left.J=8.5 \mathrm{~Hz}, \mathrm{H}-2^{\prime}, 6^{\prime}\right) ; 7.63$ (m, 2H, $\left.{ }^{4} J_{2,6}=1.8 \mathrm{~Hz}, \mathrm{H}-2,6\right) ; 6.95$ (d, $\left.2 \mathrm{H}, J=8.5 \mathrm{~Hz}, \operatorname{Ar} H, \mathrm{H}-3^{\prime}, 5^{\prime}\right) ; 6.87$ (d, $\left.1 \mathrm{H}, J=8.2 \mathrm{~Hz}, \mathrm{H}-5\right)$; $4.56(\mathrm{~m}, 1 \mathrm{H}, \mathrm{OCHO}) ; 3.92-3.82\left(\mathrm{~m}, 7 \mathrm{H}, \mathrm{CH}_{3}, \mathrm{OCHH}\right) ; 3.73(\mathrm{~m}$, $1 \mathrm{H}), 3.48(\mathrm{~m}, 3 \mathrm{H}), 3.38(\mathrm{~m}, 3 \mathrm{H})(\mathrm{OCHH}) ; 2.64(\mathrm{t}, 2 \mathrm{H}, J=7.6 \mathrm{~Hz}$, $\left.\mathrm{ArCH}_{2}\right) ; 1.88-1.38\left(\mathrm{~m}, 12 \mathrm{H}, \mathrm{OCH}_{2} \mathrm{CH}_{2} \mathrm{CH}_{2} \mathrm{CH}_{2}\right) .{ }^{13} \mathrm{C} \mathrm{NMR}$ $\left(\mathrm{DMSO}-d_{6}\right): \delta_{\mathrm{C}}=193.40(\mathrm{ArCOAr}), 162.51\left(\mathrm{C}^{\prime}\right), 160.55(\mathrm{C} 4)$, 131.84 (2C, C2',6'), 131.09 (C2), 130.23 (C3), 130.22 (C6), 129.92 (C1), $129.65\left(\mathrm{Cl}^{\prime}\right), 113.74$ (2C, C3',5'), 110.16 (C5), 97.98 (OCHO), 65.69 ( $\left.\mathrm{CH}_{2} \mathrm{OThp}\right), 61.18$ (Thp), 55.75 (4- $\left.\mathrm{OCH}_{3}\right), 55.52$ (4'-OCH $\left.\mathrm{H}_{3}\right), 32.40\left(\mathrm{CH}_{2} \mathrm{CH}_{2} \mathrm{OH}\right), 30.35$ (Thp), $29.54\left(\mathrm{ArCH}_{2}\right)$, $29.07\left(\mathrm{ArCH}_{2} \mathrm{CH}_{2}\right), 25.42\left(\mathrm{ArCH}_{2} \mathrm{CH}_{2} \mathrm{CH}_{2}\right), 25.10,19.20$ (Thp).

3-[5-( Tetrahydropyran-2-yloxy) pentyl $]-4,4^{\prime}, 4^{\prime \prime}$ - trimethoxytritanol (49). To a solution of 3-[5-(Tetrahydropyran-2-yloxy)pentyl]-4,4'-dimethoxybenzophenone (363 $\mathrm{mg}, 0.88 \mathrm{mmol}$ ) in THF $\left(5 \mathrm{~cm}^{3}\right) 1.6 \mathrm{M} 4$-methoxyphenylmagnesium bromide in THF $\left(0.75 \mathrm{~cm}^{3}, 1.2 \mathrm{mmol}\right)$ was added in one portion and the mixture was kept overnight at ambient temperature. The mixture was quenched by addition of water $\left(1 \mathrm{~cm}^{3}\right)$ and evaporated. The residue was dissolved in EtOAc $\left(30 \mathrm{~cm}^{3}\right)$, washed with $5 \% \mathrm{NaHCO}_{3}$ $\left(2 \times 10 \mathrm{~cm}^{3}\right)$, dried over $\mathrm{Na}_{2} \mathrm{SO}_{4}$ and evaporated. The desired compound was isolated by column chromatography on silica gel $\left(5 \% \mathrm{EtOAc}+1 \% \mathrm{Et}_{3} \mathrm{~N}\right.$ in toluene) as a colourless oil $(304 \mathrm{mg}$, $66 \%) . R_{\mathrm{f}} 0.49\left(20 \%\right.$ EtOAc in PhMe (v/v) $\left.+1 \% \mathrm{Et}_{3} \mathrm{~N}\right)$. ESI-TOF HRMS: $m / z=503.2771[\mathrm{M}-\mathrm{OH}]^{+}$, calc. for $\left[\mathrm{C}_{32} \mathrm{H}_{39} \mathrm{O}_{5}\right]^{+} 503.2792$. ${ }^{1} \mathrm{H} \mathrm{NMR}\left(\mathrm{DMSO}-d_{6}\right): \delta_{\mathrm{H}}=7.07\left(\mathrm{~d}, 4 \mathrm{H}, J=8.7 \mathrm{~Hz}, \mathrm{H}-2^{\prime}, 6^{\prime}, 2^{\prime \prime}, 6^{\prime \prime}\right)$; $6.99\left(\mathrm{~d}, 1 \mathrm{H},{ }^{4} \mathrm{~J}=2.3 \mathrm{~Hz}, \mathrm{H}-2\right) ; 6.87\left(\mathrm{dd}, 1 \mathrm{H}, J=8.4 \mathrm{~Hz},{ }^{4} J=\right.$

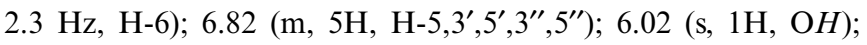
$4.50(\mathrm{~m}, 1 \mathrm{H}, \mathrm{OCHO}) ; 3.74(\mathrm{~s}, 3 \mathrm{H}), 3.72(\mathrm{~s}, 6 \mathrm{H})\left(\mathrm{OCH}_{3}\right) ; 3.69(\mathrm{~m}$, $1 \mathrm{H}), 3.57(\mathrm{~m}, 1 \mathrm{H}), 3.40(\mathrm{~m}, 1 \mathrm{H}), 3.27(\mathrm{~m}, 1 \mathrm{H})\left(2 \mathrm{OCH}_{2}\right) ; 2.47$ $\left(\mathrm{t}, 2 \mathrm{H}, J=7.4 \mathrm{~Hz}, \operatorname{ArCH}_{2}\right), 1.73-1.63(\mathrm{~m}, 1 \mathrm{H}), 1.61-1.53(\mathrm{~m}$, 1H), 1.51-1.37 (m, 8H), $1.27(\mathrm{~m}, 2 \mathrm{H})\left(2 \mathrm{OCH}_{2} \mathrm{CH}_{2} \mathrm{CH}_{2} \mathrm{CH}_{2}\right) .{ }^{13} \mathrm{C}$ NMR (DMSO- $\left.d_{6}\right): \delta_{\mathrm{C}}=157.76\left(2 \mathrm{C}, \mathrm{C}^{\prime}, 4^{\prime \prime}\right), 155.63(\mathrm{C} 4), 140.70$

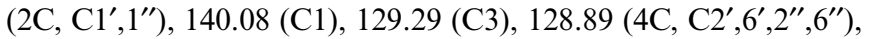
128.72 (C2), 126.37 (C6), 112.67 (4C, C3',5',3",5"), 109.33 (C5), 97.94 (OCHO), 79.68 ( $\left.\mathrm{Ar}_{3} \mathrm{COH}\right), 66.59$ ( $\left.\mathrm{CH}_{2} \mathrm{OThp}\right), 61.26$ (Thp), $55.29\left(4-\mathrm{OCH}_{3}\right), 55.01$ (2C, 4'- $\left.\mathrm{OCH}_{3}, 4^{\prime \prime}-\mathrm{OCH}_{3}\right), 30.37$ (Thp), $29.78\left(\mathrm{ArCH}_{2}\right), 29.18,29.08,25.54\left(\mathrm{ArCH}_{2} \mathrm{CH}_{2} \mathrm{CH}_{2} \mathrm{CH}_{2}\right), 25.11$, 19.23 (Thp).

3-(5-Hydroxypentyl)-4,4',4"-trimethoxytrityl methyl ether (50). To a stirred solution of 3-[5-(tetrahydropyran-2-yloxy)pentyl]$4,4^{\prime}, 4^{\prime \prime}$-trimethoxytritanol (304 mg; $\left.0.58 \mathrm{mmol}\right)$ in $\mathrm{MeOH}\left(20 \mathrm{~cm}^{3}\right)$ $\mathrm{TsOH} \cdot \mathrm{H}_{2} \mathrm{O}(10 \mathrm{mg})$ was added, and the mixture was kept at ambient temperature overnight (monitoring by TLC in EtOActoluene 1:9). Solid $\mathrm{K}_{2} \mathrm{CO}_{3}(300 \mathrm{mg}$ ) was added and the mixture was evaporated and chromatographed on silica gel in 20\% EtOAc + $1 \% \mathrm{Et}_{3} \mathrm{~N}$ in toluene. Yield $254 \mathrm{mg}(97 \%), R_{\mathrm{f}} 0.23(20 \% \mathrm{EtOAc}$ in PhMe (v/v) $\left.+1 \% \mathrm{Et}_{3} \mathrm{~N}\right)$. ESI-TOF HRMS: $m / z=419.2201$ $[\mathrm{M}-\mathrm{OMe}]^{+}$, calc. for $\left[\mathrm{C}_{27} \mathrm{H}_{31} \mathrm{O}_{4}\right]^{+} 419.2217 .{ }^{1} \mathrm{H}$ NMR (DMSO- $d_{6}$ ): $\delta_{\mathrm{H}}=7.24\left(\mathrm{~d}, 4 \mathrm{H}, J=8.5 \mathrm{~Hz}, \mathrm{H}-2^{\prime}, 6^{\prime}, 2^{\prime \prime}, 6^{\prime \prime}\right) ; 7.10(\mathrm{dd}, 1 \mathrm{H}, J=$ $\left.8.5 \mathrm{~Hz},{ }^{4} \mathrm{~J}=2.1 \mathrm{~Hz}, \mathrm{H}-6\right) ; 7.07$ (d, $\left.1 \mathrm{H},{ }^{4} \mathrm{~J}=2.1 \mathrm{~Hz}, \mathrm{H}-2\right) ; 6.88$ $\left(\mathrm{m}, 5 \mathrm{H}, \mathrm{H}-5,3^{\prime}, 5^{\prime}, 3^{\prime \prime}, 5^{\prime \prime}\right) ; 4.30(\mathrm{t}, 1 \mathrm{H}, J=5.0 \mathrm{~Hz}, \mathrm{OH}) ; 3.76(\mathrm{~s}$, $3 \mathrm{H}), 3.74(\mathrm{~s}, 3 \mathrm{H})\left(\mathrm{ArOCH}_{3}\right) ; 3.36\left(\mathrm{~m}, 2 \mathrm{H}, \mathrm{CH}_{2} \mathrm{OH}\right), 2.92(\mathrm{~s}, 3 \mathrm{H}$, $\left.\mathrm{Ar}_{3} \mathrm{COCH}_{3}\right) ; 2.49$ (t, 2H, $\left.J=7.4 \mathrm{~Hz}, \mathrm{ArCH}_{2}\right) ; 1.49-1.36(\mathrm{~m}, 4 \mathrm{H}$, $\mathrm{ArCH}_{2} \mathrm{CH}_{2} \mathrm{CH}_{2} \mathrm{CH}_{2}$ ); 1.25 (m, 2H, $\left.\mathrm{ArCH}_{2} \mathrm{CH}_{2} \mathrm{CH}_{2}\right) .{ }^{13} \mathrm{C} \mathrm{NMR}$
(DMSO- $\left.d_{6}\right): \delta_{\mathrm{C}}=157.90\left(2 \mathrm{C}, \mathrm{C}^{\prime}, 4^{\prime \prime}\right), 155.76(\mathrm{C} 4), 136.42(2 \mathrm{C}$, $\left.\mathrm{C} 1^{\prime}, 1^{\prime \prime}\right), 135.58(\mathrm{C} 1), 129.76(\mathrm{C} 3), 129.42\left(4 \mathrm{C}, \mathrm{C} 2^{\prime}, 6^{\prime}, 2^{\prime \prime}, 6^{\prime \prime}\right), 128.93$ (C2), 126.99 (C6), 113.08 (4C, C3',5',3", 5"), 109.83 (C5), 85.61 $\left(\mathrm{Ar}_{3} \mathrm{COCH}_{3}\right), 60.78\left(\mathrm{CH}_{2} \mathrm{OH}\right), 55.31\left(4-\mathrm{OCH}_{3}\right), 55.03\left(2 \mathrm{C}, 4^{\prime}-\right.$ $\mathrm{OCH}_{3}, 4$ "'-OCH$\left.)_{3}\right), 51.24\left(\mathrm{Ar}_{3} \mathrm{COCH}_{3}\right), 32.43,29.82,29.30,25.28$ $\left(\mathrm{ArCH} \mathrm{H}_{2} \mathrm{CH}_{2} \mathrm{CH}_{2} \mathrm{CH}_{2}\right)$.

3-[5-(1-Maleimido)pentyl]-4,4',4"-trimethoxytritanol (52). To a stirred solution of 3-(5-hydroxypentyl)-4,4',4"'-trimethoxytrityl methyl ether $(642 \mathrm{mg} ; 1.42 \mathrm{mmol})$ in toluene $\left(10 \mathrm{~cm}^{3}\right)$ maleimide (152 mg, $1.57 \mathrm{mmol}), \mathrm{PPh}_{3}(410 \mathrm{mg}, 1.57 \mathrm{mmol})$ were added followed by DEAD $\left(0.26 \mathrm{~cm}^{3}, 1.64 \mathrm{mmol}\right)$. The mixture was kept at ambient temperature for $24 \mathrm{~h}$ (monitoring by TLC in $20 \%$ EtOAc in $\mathrm{PhMe}(\mathrm{v} / \mathrm{v})+1 \% \mathrm{Et}_{3} \mathrm{~N} ; R_{\mathrm{f}} 0.52$ (intermediate 51), and evaporated. The crude compound $\mathbf{5 1}$ was dissolved in toluene $\left(10 \mathrm{~cm}^{3}\right)$. Trifluoroacetic acid $\left(0.22 \mathrm{~cm}^{3}, 2.84 \mathrm{mmol}\right)$ was added and after 10 minutes the mixture was quenched by saturated aqueous $\mathrm{NaHCO}_{3}$. Organic layer was separated and washed with aqueous $\mathrm{NaHCO}_{3}\left(10 \mathrm{~cm}^{3}\right)$, water $\left(10 \mathrm{~cm}^{3}\right)$ and brine $\left(10 \mathrm{~cm}^{3}\right)$, dried over $\mathrm{Na}_{2} \mathrm{SO}_{4}$ and evaporated. The residue was chromatographed on silica gel in $10 \rightarrow 18 \%$ EtOAc in toluene $+1 \% \mathrm{Et}_{3} \mathrm{~N}$. Yield $384 \mathrm{mg}$ $(51 \%) . R_{\mathrm{f}} 0.42\left(20 \%\right.$ EtOAc in PhMe $\left.(\mathrm{v} / \mathrm{v})+1 \% \mathrm{Et}_{3} \mathrm{~N}\right)$. ESITOF HRMS: $m / z=498.2290[\mathrm{M}-\mathrm{OH}]^{+}$, calc. for $\left[\mathrm{C}_{31} \mathrm{H}_{32} \mathrm{NO}_{5}\right]^{+}$ 498.2275. ${ }^{1} \mathrm{H}$ NMR (DMSO- $d_{6}$ ): $\delta_{\mathrm{H}}=7.07(\mathrm{~d}, 4 \mathrm{H}, J=8.7 \mathrm{~Hz}$, $\left.\mathrm{H}-2^{\prime}, 6^{\prime}, 2^{\prime \prime}, 6^{\prime \prime}\right) ; 6.98(\mathrm{~s}, 2 \mathrm{H}, \mathrm{COC} H=\mathrm{CHCO}) ; 6.96\left(\mathrm{~d}, 1 \mathrm{H},{ }^{4} J_{2,6}=\right.$ $2.1 \mathrm{~Hz}, \mathrm{H}-2) ; 6.86\left(\mathrm{dd}, 1 \mathrm{H},{ }^{4} J_{2,6}=2.1 \mathrm{~Hz}, J=8.5 \mathrm{~Hz}, \mathrm{H}-6\right)$; 6.85-6.79 (m, 5H, H-5, 3', 5', $\left.3^{\prime \prime}, 5^{\prime \prime}\right) ; 6.01$ (s, 1H, OH); 3.74 (s, 3H), $3.72(\mathrm{~s}, 6 \mathrm{H})\left(\mathrm{OCH}_{3}\right) ; 3.34\left(\mathrm{t}, 2 \mathrm{H}, J=7.4 \mathrm{~Hz}, \mathrm{NCH}_{2}\right) ; 2.43(\mathrm{t}$, $\left.2 \mathrm{H}, J=7.4 \mathrm{~Hz}, \mathrm{ArCH}_{2}\right) ; 1.45\left(\mathrm{~m}, 4 \mathrm{H}, \mathrm{ArCH}_{2} \mathrm{CH}_{2} \mathrm{CH}_{2} \mathrm{CH}_{2}\right)$; $1.19\left(\mathrm{~m}, 2 \mathrm{H}, \mathrm{ArCH}_{2} \mathrm{CH}_{2} \mathrm{CH}_{2}\right) \cdot{ }^{13} \mathrm{C} \mathrm{NMR}\left(\mathrm{DMSO}-d_{6}\right): \delta_{\mathrm{C}}=$ 171.07 (2C, CO), 157.76 (2C, C4',4"), 155.63 (C4), 140.69 (2C, $\left.\mathrm{Cl}^{\prime}, 1^{\prime \prime}\right), 140.10(\mathrm{C} 1), 134.45(2 \mathrm{C}, \mathrm{COCH}=\mathrm{CHCO}), 129.20$ (C3), 128.89 (4C, C2', 6', 2", 6" ), 128.60 (C2), 126.40 (C6), 112.70 (4C, $\left.\mathrm{C}^{\prime}, 5^{\prime}, 3^{\prime \prime}, 5^{\prime \prime}\right), 109.35(\mathrm{C} 5), 79.67(\mathrm{COH}), 55.31\left(4-\mathrm{OCH}_{3}\right), 55.02$ $\left(2 \mathrm{C}, 4^{\prime}-\mathrm{OCH}_{3}, 4^{\prime \prime}-\mathrm{OCH}_{3}\right), 37.06\left(\mathrm{CH}_{2} \mathrm{~N}\right), 29.56\left(\mathrm{ArCH}_{2}\right), 28.89$, 27.77, $25.89\left(\mathrm{ArCH}_{2} \mathrm{CH}_{2} \mathrm{CH}_{2} \mathrm{CH}_{2}\right)$.

\section{Labelling procedures}

NHS-ester Labelling. The labelling reaction was carried out with freshly made $0.02 \mathrm{M}$ stock solution of the water-soluble labelling reagent 16a dissolved in $80 \%$ 200mM $\mathrm{NaHCO}_{3} / 20 \%$ acetonitrile. $4 \mathrm{~mm}^{3}$ of this stock solution was added to $25 \mathrm{~mm}^{3}$ (200 pmol) of Glu-Fib-K peptide in $80 \% 200 \mathrm{mM} \mathrm{NaHCO}_{3} / 20 \%$ acetonitrile and left for $1 \mathrm{~h}$ at room temperature. $2 \mathrm{~mm}^{3}$ of the reaction mixture was purified by micro-extraction and before MALDI-TOF MS analysis. The sample was diluted with $0.1 \%$ trifluoroacetic acid (TFA) $\left(15 \mathrm{~mm}^{3}\right)$ and applied to $\mathrm{C}_{18}$ Zip Tip (prepared by washing with $99.9 \% \mathrm{MeCN} / 0.1 \%$ TFA $\left(3 \times 10 \mathrm{~mm}^{3}\right)$ followed by $0.1 \%$ TFA $\left.\left(3 \times 10 \mathrm{~mm}^{3}\right)\right)$. The sample was applied to $\mathrm{C}_{18}$ Zip Tip and passed through 5-6 times. The Zip Tip was washed with $0.1 \%$ TFA $\left(5 \times 10 \mathrm{~mm}^{3}\right)$, and peptides were eluted with $50 \%$ MeCN/0.1\% TFA $\left(3 \mathrm{~mm}^{3}\right) .0 .2 \mathrm{~mm}^{3}$ of the eluted sample was mixed with $\alpha$-cyano-4-hydroxycinnamic acid in 50\% MeCN/ $0.1 \%$ TFA $\left(10 \mathrm{mg} / \mathrm{cm}^{3} ; 0.2 \mathrm{~mm}^{3}\right)$ and applied onto MALDI target plate.

Maleimido-activated trityl Labelling. The labelling reaction was carried out with freshly made $0.02 \mathrm{M}$ stock solution of the maleimido labelling reagent $\mathbf{5 2}$ dissolved in acetonitrile. $4 \mathrm{~mm}^{3}$ of this stock solution was added to $25 \mathrm{~mm}^{3}$ (200 pmol) of Laminin 
peptide in either acetonitrile or pyridine. This was left shaking for 30 mintutes at room temperature. $1 \mathrm{~mm}^{3}$ of the reaction mixture was purified by micro-extraction and before MALDI-TOF MS analysis. The sample was diluted with $0.1 \%$ trifluoroacetic acid (TFA) $\left(12 \mathrm{~mm}^{3}\right)$ and purified on $\mathrm{C}_{18}$ Zip Tip and analysed as above.

\section{Conclusions}

We have designed functionalised trityl MTs for MS applications. This work has produced a large number of different trityl structures of which a few have been tested as possible mass tags. The MS studies of peptide conjugates reported here are initial results for four selected trityl derivatives. These MTs were used for labelling of trypsin digests and yielded more detectable peptides (higher MASCOT score) than corresponding non-labelled mixtures; trityl MT labelling also improved some aspects of ESI-MS studies. Although some of these MTs have shown an enhancement of signal for the conjugated peptides, we have also seen some derivatives that, surprisingly, suppress the signal (e.g. Fig. 8, 17f and 28j). We are continuing to optimise the design of functionalised trityl MTs for MS applications (mainly in the proteomic field), and more development must be carried out to further investigate this trend with a wider range of peptides. We are also in the process of developing more efficient methods for labelling including a solidphase method.

\section{Acknowledgements}

The authors are grateful to Susan Wheeler, Claire Abrahams, Zakhar O. Shenkarev, Larisa V. Gruzintseva for useful discussions and helpful advice. NMR spectra were kindly provided by the Shemyakin-Ovchinnikov Institute NMR Spectrometry Facility (registry No. 98-03-08), high resolution mass spectra were kindly provided by the Oxford University Mass Spectrometry Facility.

\section{References}

1 (a) M. Karas, D. Bachmann and F. Hillenkamp, Anal. Chem., 1985, 57, 2935; (b) J. B. Fenn, Angew. Chem. Int. Ed., 2003, 42, 3871; (c) C. S. Lane, Cell. Mol. Life Sci., 2005, 62, 848; (d) B. Domon and R. Aebersold, Science, 2006, 312, 212; (e) B. F. Cravatt, G. M. Simon and J. R. Yates, III, Nature, 2007, 450, 991.

2 (a) S. A. Hofstadler, K. A. Sannes-Lowery and J. C. Hannis, Mass Spec. Rev., 2005, 24, 265; (b) B. Thomas and A. V. Akoulitchev, Trends Biochem. Sci., 2006, 31, 173; (c) S. Douthwaite and F. Kirpekar, Meth. Enzymol., 2007, 425, 3.

3 (a) J. Zaia, Mass Spec. Rev., 2004, 23, 161; (b) D. J. Harvey, Proteomics, 2005, 5, 1774; (c) Y. Park and C. B. Lebrilla, Mass Spec. Rev., 2005, 24, 232; (d) D. J. Harvey, Mass Spec. Rev., 2008, 27, 125.
4 (a) S. G. Villas-Bôas, S. Mas, M. Åkesson, J. Smedsgaard and J. Nielsen, Mass Spec. Rev., 2005, 24, 613; (b) S. C. Brown, G. Kruppa and J.-L. Dasseux, Mass Spec. Rev., 2005, 24, 223; (c) K. Dettmer, P. A. Aronov and B. D. Hammock, Mass Spec. Rev., 2007, 26, 51.

5 (a) P. G. Righetti, N. Campostrini, J. Pascali, M. Hamdan and H. Astner, Eur. J. Mass Spectrom., 2004, 10, 335-348; (b) B. Bogdanov and R. D. Smith, Mass Spec. Rev., 2005, 24, 168; (c) J. M. Asara, M. N. Schweitzer, L. M. Freimark, M. Phillips and L. C. Cantley, Science, 2007, 316, 280; (d) M.-Q. Dong, J. D. Venable, N. Au, T. Xu, S. K. Park, D. Cociorva, J. R. Johnson, A. Dillin and J. R. Yates, III, Science, 2007, 317, 660 .

6 M. S. Shchepinov, R. Chalk and E. M. Southern, Tetrahedron, 2000, 56, 2713 .

7 (a) M. S. Shchepinov, R. Chalk and E. M. Southern, Nucleic Acids Symp. Ser., 1999, 42, 107; (b) K. R. Birikh, V. A. Korshun, P. L. Bernad, A. D. Malakhov, N. Milner, S. Khan, E. M. Southern and M. S. Shchepinov, Anal. Chem., 2008, 80, 2342.

8 (a) S. F. Wheeler, V. A. Korshun, E. M. Southern, and M. S. Shchepinov, $52^{\text {nd }}$ ASMS Conference, Nashville, Tennessee, 2004; $(b)$ G. Thiery, M. S. Shchepinov, E. M. Southern, A. Audebourg, V. Audard, B. Terris and I. Gut, Rapid Commun. Mass Spectrom., 2007, 21, 823; (c) G. Thiery, E. Anselmi, A. Augebourg, E. Darii, M. Abarbri, B. Terris, J.-C. Tabet and I. G. Gut, Proteomics, 2008, 8, 3725.

9 (a) B. Spengler, F. Luetzenkirchen, S. Metzger, P. Chaurand, R. Kaufman, W. Jeffrey, M. Bartlet-Jones and D. J. C. Pappin, Int. J. Mass Spectrom. Ion Proc., 1997, 169/170, 127; (b) K. D. W. Roth, Z.-H. Huang, N. Sadagopan and J. T. Watson, Mass Spec. Rev., 1998, 17, 255

10 (a) D. S. Wagner, A. Salari, D. A. Gage, J. Leykam, J. Fetter, R. Hollingsworth and J. T. Watson, Biol. Mass-Spectrom., 1991, 20, 419; (b) Z.-H. Huang, J. Wu, K. D. W. Roth, Y. Yang, D. A. Gage and J. T. Watson, Anal. Chem, 1997, 69, 137.

11 J. Zaia and K. Biemann, J. Am. Soc. Mass-Spectrom., 1995, 6, 428.

12 N. C. Deno, J. J. Jaruzelski and A. Schriesheim, J. Am. Chem. Soc., $1955,77,3044$

13 J. C. Martin and R. G. Smith, J. Am. Chem. Soc., 1964, 86, 2252.

14 M. S. Shchepinov and V. A. Korshun, Chem. Soc. Rev., 2003, 32, 170.

15 M. S. Shchepinov, V. A. Korshun, R. D. Egeland and E. M. Southern, Tetrahedron Lett., 2000, 41, 4943.

16 (a) S. Khan, P. Bernad, V. A. Korshun, E. M. Southern and M. S. Shchepinov, Synlett, 2005, 2453; (b) P. Bernad Jr., S. Khan, V. A. Korshun, E. M. Southern and M. S. Shchepinov, Chem. Comm., 2005, 3466.

17 (a) S. P. Gygi, B. Rist, S. A. Gerber, F. Turecek, M. H. Gelb and R. Aebersold, Nature Biotechnol., 1999, 17, 994; (b) E. C. Yi, X. Li, K. Cooke, H. Lee, B. Raught, A. Page, V. Aneliunas, P. Hieter, D. R. Goodlett and R. Aebersold, Proteomics, 2005, 5, 380.

18 R. Rathore, C. L. Burns and I. A. Guzei, J. Org. Chem., 2004, 69, 1524

19 J. D. Reynolds and K. D. Cook, Int. J. Mass Spectrom. Ion Proc., 1990, 97, 325.

20 (a) M. Shahgholi, Ph.D Thesis, University of Tennessee at Knoxville, 1993; (b) S. Zhou and K. D. Cook, J. Am. Soc. Mass Spectrom., 2000, 11, 961

21 E. Krause, H. Wenschuh and P. R. Jungblut, Anal. Chem., 1999, 71, 4160.

22 Peptides were synthesised and purified by Activotec (http://www.activotec.com/).

23 S. Wheeler, M. S. Shchepinov, and E. M. Southern, (2005) Pat. $\mathrm{WO} / 2005 / 057221$.

24 H. E. Gottlieb, V. Kotlyar and A. Nudelman, J. Org. Chem., 1997, 62, 7512. 